\title{
Ocean sea-ice modelling in the Southern Ocean around Indian Antarctic stations
}

\author{
Anurag Kumar ${ }^{1}$, Suneet Dwivedi ${ }^{1, *}$ and D Ram RajaK ${ }^{2}$ \\ ${ }^{1} K$ Banerjee Centre of Atmospheric and Ocean Studies and M N Saha Centre of Space Studies, \\ University of Allahabad, Allahabad 211 002, India. \\ ${ }^{2}$ Space Application Centre, Indian Space Research Organisation, Ahmedabad 380 015, India. \\ *Corresponding author.e-mail: suneetdwivedi@gmail.com
}

MS received 20 July 2016; revised 13 December 2016; accepted 23 February 2017; published online 21 July 2017

An eddy-resolving coupled ocean sea-ice modelling is carried out in the Southern Ocean region $\left(9^{\circ}-78^{\circ} \mathrm{E}\right.$; $\left.51^{\circ}-71^{\circ} \mathrm{S}\right)$ using the MITgcm. The model domain incorporates the Indian Antarctic stations, Maitri $\left(11.7^{\circ} \mathrm{E} ; 70.7^{\circ} \mathrm{S}\right)$ and Bharati $\left(76.1^{\circ} \mathrm{E} ; 69.4^{\circ} \mathrm{S}\right)$. The realistic simulation of the surface variables, namely, sea surface temperature (SST), sea surface salinity (SSS), surface currents, sea ice concentration (SIC) and sea ice thickness (SIT) is presented for the period of 1997-2012. The horizontal resolution of the model varies between 6 and $10 \mathrm{~km}$. The highest vertical resolution of $5 \mathrm{~m}$ is taken near the surface, which gradually increases with increasing depths. The seasonal variability of the SST, SSS, SIC and currents is compared with the available observations in the region of study. It is found that the SIC of the model domain is increasing at a rate of $0.09 \%$ per month (nearly $1 \%$ per year), whereas, the SIC near Maitri and Bharati regions is increasing at a rate of 0.14 and $0.03 \%$ per month, respectively. The variability of the drift of the sea-ice is also estimated over the period of simulation. It is also found that the sea ice volume of the region increases at the rate of $0.0004 \mathrm{~km}^{3}$ per month (nearly $0.005 \mathrm{~km}^{3}$ per year). Further, it is revealed that the accumulation of sea ice around Bharati station is more as compared to Maitri station.

Keywords. Sea ice concentration; sea ice thickness; sea surface temperature; sea surface salinity; southern Ocean.

\section{Introduction}

The Southern Ocean (SO) plays a significant role in influencing the global climate. The SO waters are connected to the other oceans through a conveyor belt system (Lucas et al. 2014). The surface fluxes of both mass and buoyancy have a prominent effect on the SO dynamics (including water mass conversion and formation) which makes the SO important for the global overturning circulation (Rintoul et al. 2001). The zonal wind stress in the SO generates a strong eastward flow called the
Antarctic Circumpolar Current (ACC) (Trenberth et al. 1990; Orsi et al. 1995). The large volume transport by the ACC is one of the important features of the SO. The SO is also the world's largest oceanic sink of $\mathrm{CO}_{2}$ (Patra et al. 2005) and wind energy (Wunsch 1998). The small scale $(<18 \mathrm{~km})$ eddies play a significant role in the $\mathrm{SO}$ variability (Marshall et al. 1993). The variability and circulation of the SO, however, is poorly understood due to lack of quality high-resolution observations.

The sea ice exists as a thin layer at the interface of the ocean and atmosphere, and forms due 
to freezing of seawater. It is quite sensitive to small changes in temperature and radiative forcing. The ice-albedo feedback mechanism greatly enhances the climate response (Lemke et al. 2007; Li et al. 2013). The sea ice controls the fluxes of heat, moisture and momentum across the ocean-atmosphere interface. The inclusion of salt in the sea ice alters its thermal and morphological properties (Hunke et al. 2010). The formation and melting of the sea ice prominently influences the ocean surface variables. When the sea ice forms it ejects brine, which increases the surface salinity (thus making the water denser) and provides negative buoyancy flux to the ocean (resulting into downwards flow as a part of the deep-water circulation), whereas, its melting freshens the surface ocean and provides a positive buoyancy flux (Kusahara et al. 2011). Therefore, the seasonality of the sea ice growth and melting plays a vital role in the sea surface salinity variability, which in turn affects the density and stratification of water masses at high latitudes, thus influencing global ocean water mass circulation (Rooth 1982; Warren 1983). The surface temperature of the polar regions has a key role in sea ice growth, melt and surface atmosphere energy exchange.

The Antarctica sea ice extent (SIE) is significantly increasing since 1979 (Parkinson and Cavalieri 2012). The highest seasonal change in the Antarctica SIE is observed during the late summer (Turner et al. 2013). Kurtz and Markus (2012) used satellite data to show that the Antarctica sea ice thickness exhibits a small negative trend, whereas, the sea ice area increases in the summer. On one hand, the Arctic sea ice coverage is disappearing fast, the Antarctic sea ice coverage is gradually expanding since 1970 on the other (Cavalieri et al. 2003; Zhang 2007). The studies performed using the coupled climate models on the other hand depict decrease in the Antarctica sea ice with increasing greenhouse gases and stratosphere ozone depletion (Bitz et al. 2006; Sigmond and Fyfe 2010; Mahlstein et al. 2013; Polvani and Smith 2013; Swart and Fyfe 2013).

The SO sea ice immensely affects the world climate by modulating the exchange of heat between the ocean and atmosphere. The formation and melting of the sea ice takes place in both the hemispheres. However, compared to the Arctic, sea ice of the SO influences the global climate strongly because of its vast cover and deep-water formation (Fletcher 1969; Walsh 1983). The SO uptake of $\mathrm{CO}_{2}$, which provides a vital habitat for marine organisms (Thomas and Dieckmann 2002) also gets influenced by the sea ice (Takahashi et al. 2009). The freezing and melting of the sea ice also controls the amount and location of deep and bottom water formation in the marginal seas of the SO (Timmermann et al. 2005). The changes in the SO (and Antarctic) sea ice variability are also shown to be teleconnected to mid-latitudes (Grumbine 1994; Kidston et al. 2011; Bader et al. 2013) and tropics (Yuan and Martinson 2000; Martinson and Iannuzzi 2003; Yuan 2004).

Due to dominant role of eddies, intense wind stratification, and high latitude sea ice dynamics in the SO, the simulation of physical and dynamical processes of this area has always been challenging. Several modelling (sensitivity) studies have been performed to understand southern ocean sea ice variability (Zhang 2007; Stossel et al. 2011; Holland et al. 2014) including the effects of surface precipitation (Powell et al. 2005), winds (Stossel et al. 2011) and ice-shelf melt water (Hellmer 2004). The models have been validated against ice observations with notable success (Timmermann et al. 2002, 2005, 2009; Timmermann and Beckmann 2004; Fichefet et al. 2003; Losch et al. 2010).

The contribution of wind energy and carbon containing gases, global overturning circulation, formation of ACC and Antarctic Bottom Water (AABW), and the distinctive high latitude physical processes occurring due to formation and melting of sea ice make the SO sea ice variability important and unique in some respect. For this purpose, the correct estimation of the SO hydrography and sea ice variability (concentration, thickness, and volume) is highly desirable. However, the availability of continuous in time high-resolution sea ice data is inadequate. The observations are limited for obvious regions and the model output is available from coarse resolution global runs. Moreover, compared to the Atlantic and Pacific sectors of the SO, its Indian Ocean sector has remained largely unexplored. This, therefore, limits our understanding of the meso-scale processes occurring around the Indian Antarctic stations.

India has currently two permanent stations in Antarctic, namely, Maitri $\left(11.7^{\circ} \mathrm{E} ; 70.7^{\circ} \mathrm{S}\right)$ and Bharati $\left(76.1^{\circ} \mathrm{E} ; 69.4^{\circ} \mathrm{S}\right)$. These stations are $2323 \mathrm{~km}$ apart from each other in the Indian Ocean sector. Maitri station is in land ice region and is far from ocean. On the other hand, Bharati station in Larseman Hills region is a coastal station close to ocean. The sea ice variability is, therefore, 
very different at these locations. One of the primary aims of the manuscript is to understand this difference. Another aim of the manuscript is to run a limited area regional high-resolution ocean circulation model with sea ice package and realistic physics in the SO region covering the Indian Antarctic stations. Effort has been made to simulate the sea surface temperature (SST), sea surface salinity (SSS), sea ice concentration (SIC), sea ice thickness (SIT) and surface ocean current. The paper is organized as follows: section 2 gives a brief account of the ocean sea ice model configuration. The results and discussion are given in section 3. Conclusions are in section 4 .

\section{Ocean sea ice model configuration}

The ocean circulation model, which we use for our study is the MITgcm (Marshall et al. 1997), which is an z-coordinate model. The z-coordinate system has been found useful in avoiding the difficult issue of vanishing levels under the thick ice (Campin et al. 2008). Our model setup uses the hydrostatic and Boussinesq approximations. The MITgcm is configured to run in the region $\left(9^{\circ}-78^{\circ} \mathrm{E} ; 51^{\circ}-71^{\circ} \mathrm{S}\right)$ of the $\mathrm{SO}$. The region covers both the Indian Antarctic stations, namely, Maitri $\left(11.7^{\circ} \mathrm{E} ; 70.7^{\circ} \mathrm{S}\right)$ and Bharati $\left(76.1^{\circ} \mathrm{E} ; 69.4^{\circ} \mathrm{S}\right)$. We run the model at an eddy resolving horizontal resolution of nearly $6-10 \mathrm{~km}$. The model uses 28

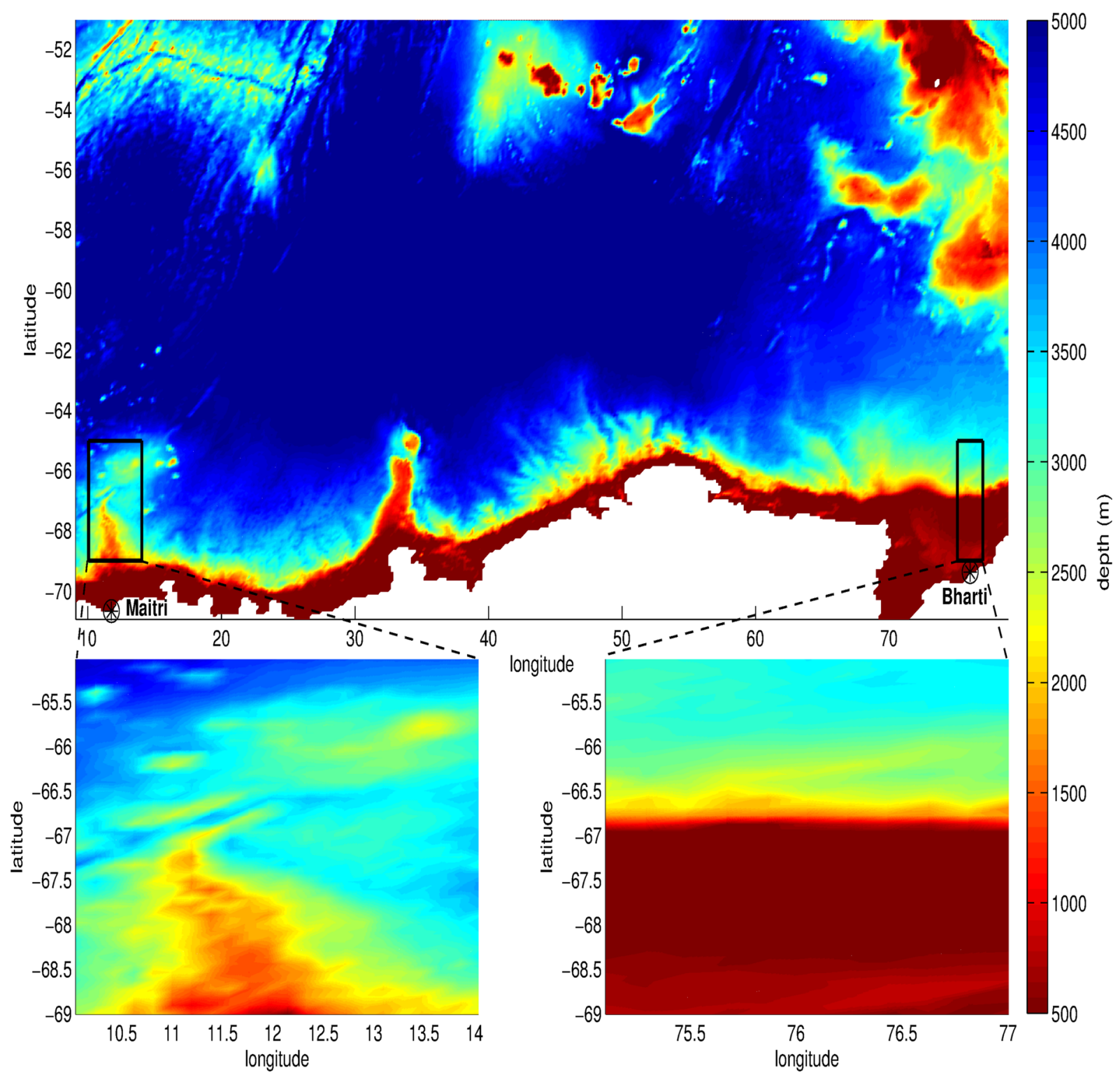

Figure 1. Bathymetry of the model domain in the Southern Ocean around $\left(9^{\circ}-78^{\circ} \mathrm{E} ; 51^{\circ}-71^{\circ} \mathrm{S}\right)$. Maitri and Bharati stations are marked by circle. The bathymetry of the zoomed portion of the rectangular regions in the southwestern and southeastern parts of the model domain is shown in the bottom left and bottom right panels, respectively. 
levels in vertical. The highest vertical resolution is taken as $5 \mathrm{~m}$ near the surface, which gradually increases with the depth. The model uses the non-linear equation of state following Jackett and Mcdougall (1995). A non-linear third-order direct space-time flux limiter advection scheme is used. We use no-slip condition on sides and take bottom frictional drag coefficient as 0.001. The vertical Laplacian frictional dissipation coefficient and the vertical diffusion coefficient for temperature and salinity are taken as $10^{-5} \mathrm{~m}^{2} / \mathrm{s}$. The non-dimensional grid size dependent eddy viscosity and bi-harmonic viscosity are taken as 0.1 and 0.01 , respectively. The bathymetry of the model (figure 1) is derived from the high-resolution (1') topography data of Smith and Sandwell (1997). We force the model by daily NCEP reanalysis (Kalnay et al. 1996) air-sea forcing fields, namely, zonal and meridional winds at $10 \mathrm{~m}$, air temperature at $2 \mathrm{~m}$, precipitation, specific humidity, downward shortwave radiation and long wave radiation. These forcing fields are converted to corresponding fluxes (a)

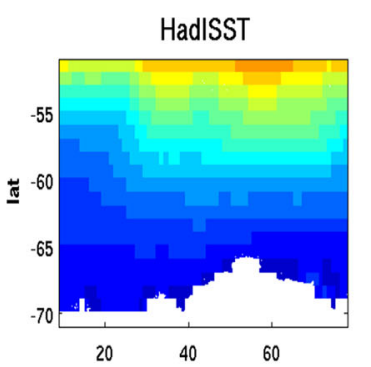

SSS

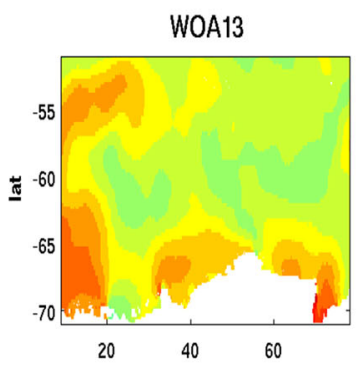

SSMII

SIC

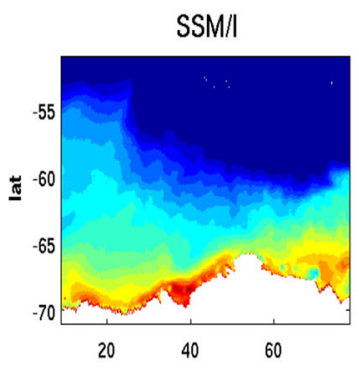

GECCO2

$\mathrm{SIT}(\mathrm{m})$

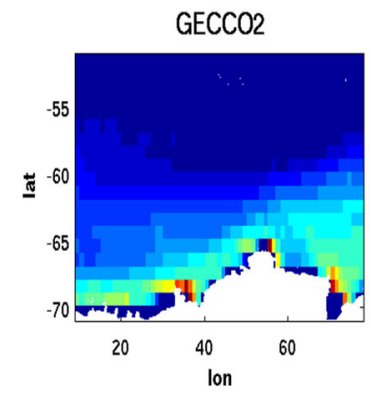

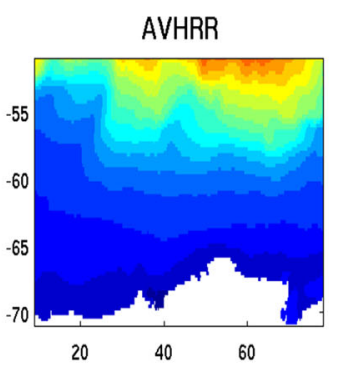

SOSE

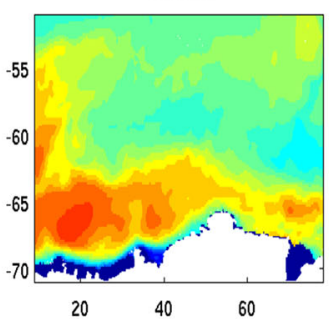

HadISIC

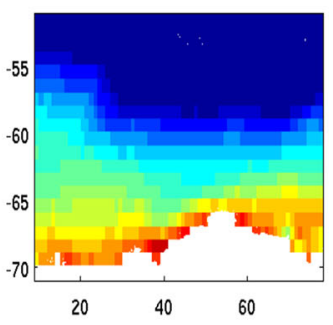

SOSE

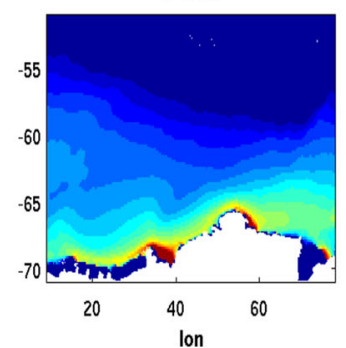

GIOMAS

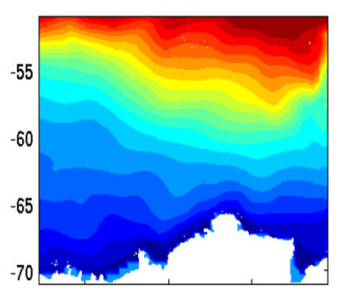

GIOMAS

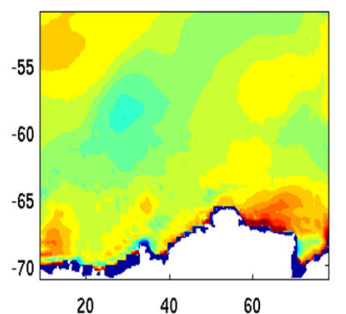

GIOMAS

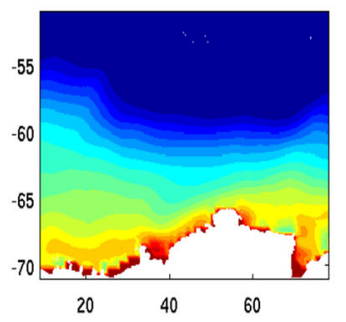

GIOMAS

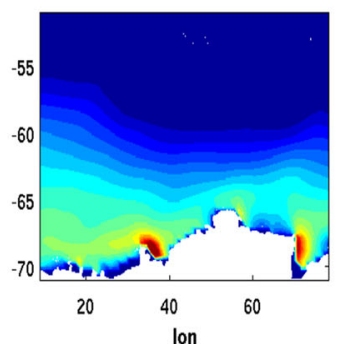

Model

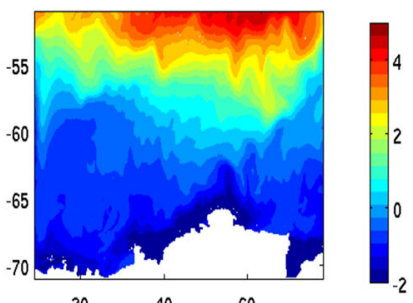

$20 \quad 40 \quad 60$

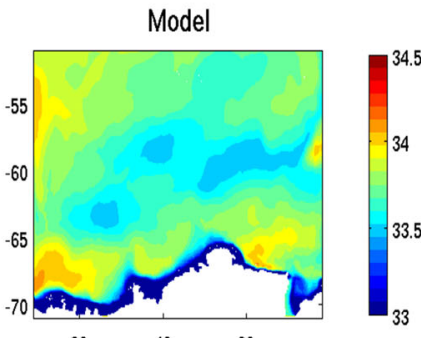

$20 \quad 40 \quad 60$

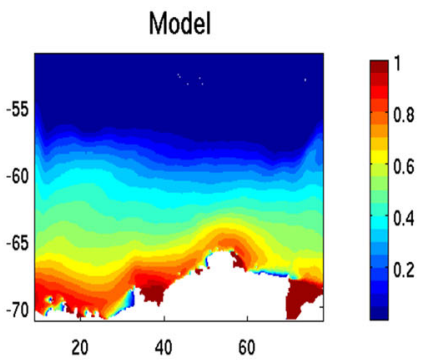

Model

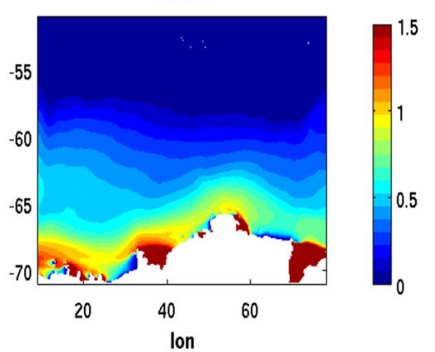

Figure 2. (a) Climatological map of model SST, SSS, SIC and SIT during 1997-2012. (1st row) Model SST is compared with HadISST, AVHRR and GIOMAS observations; (2nd row) Model SSS is compared with WOA13, SOSE and GIOMAS observations; (3rd row) Model SIC is compared with SSM/I, HadISIC and GIOMAS observations; (4th row) Model SIT is compared with GECCO2, SOSE and GIOMAS observations. (b) Bias map of model SST (1st row), SSS (2nd row), SIC (3rd row) and SIT (4th row) with respect to observations given in (a) above during 1997-2012. 
(b)
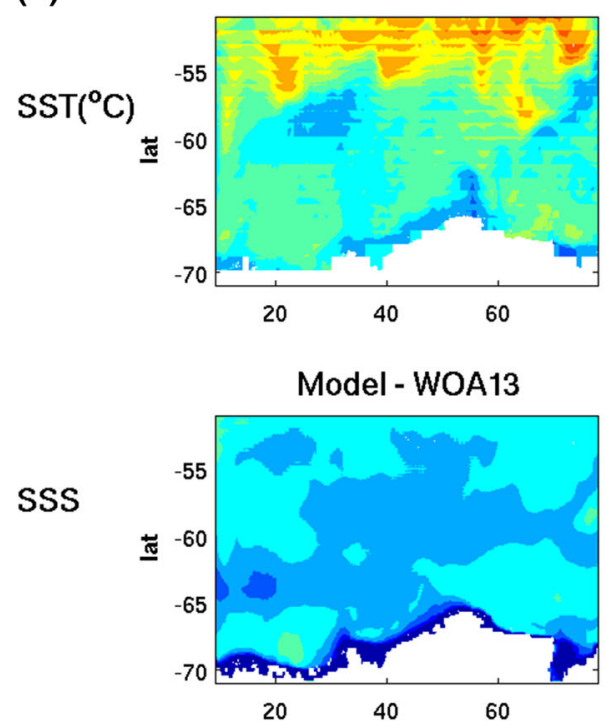

Model - SSM/I

$\mathrm{SIC}$

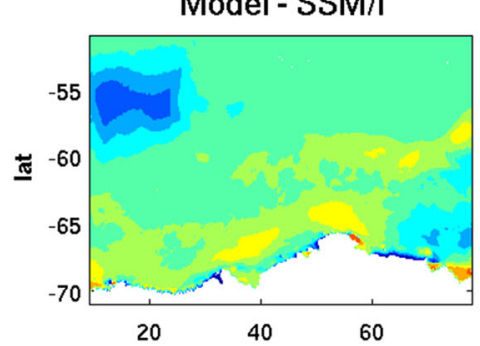

Model - GECCO2

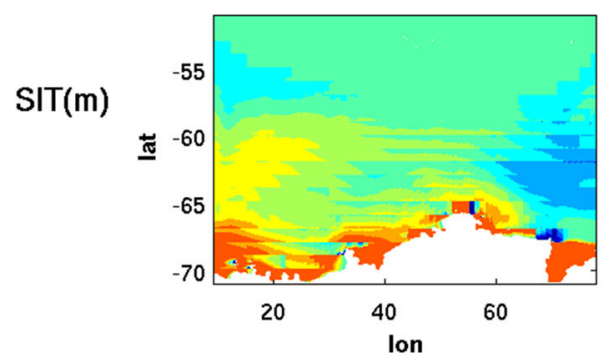

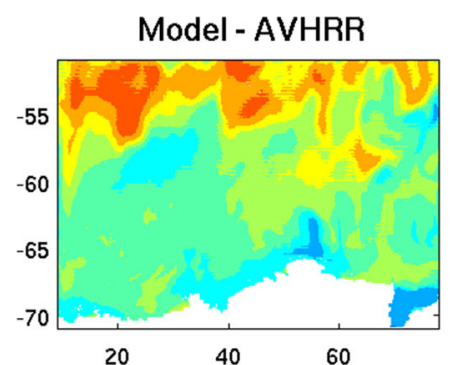
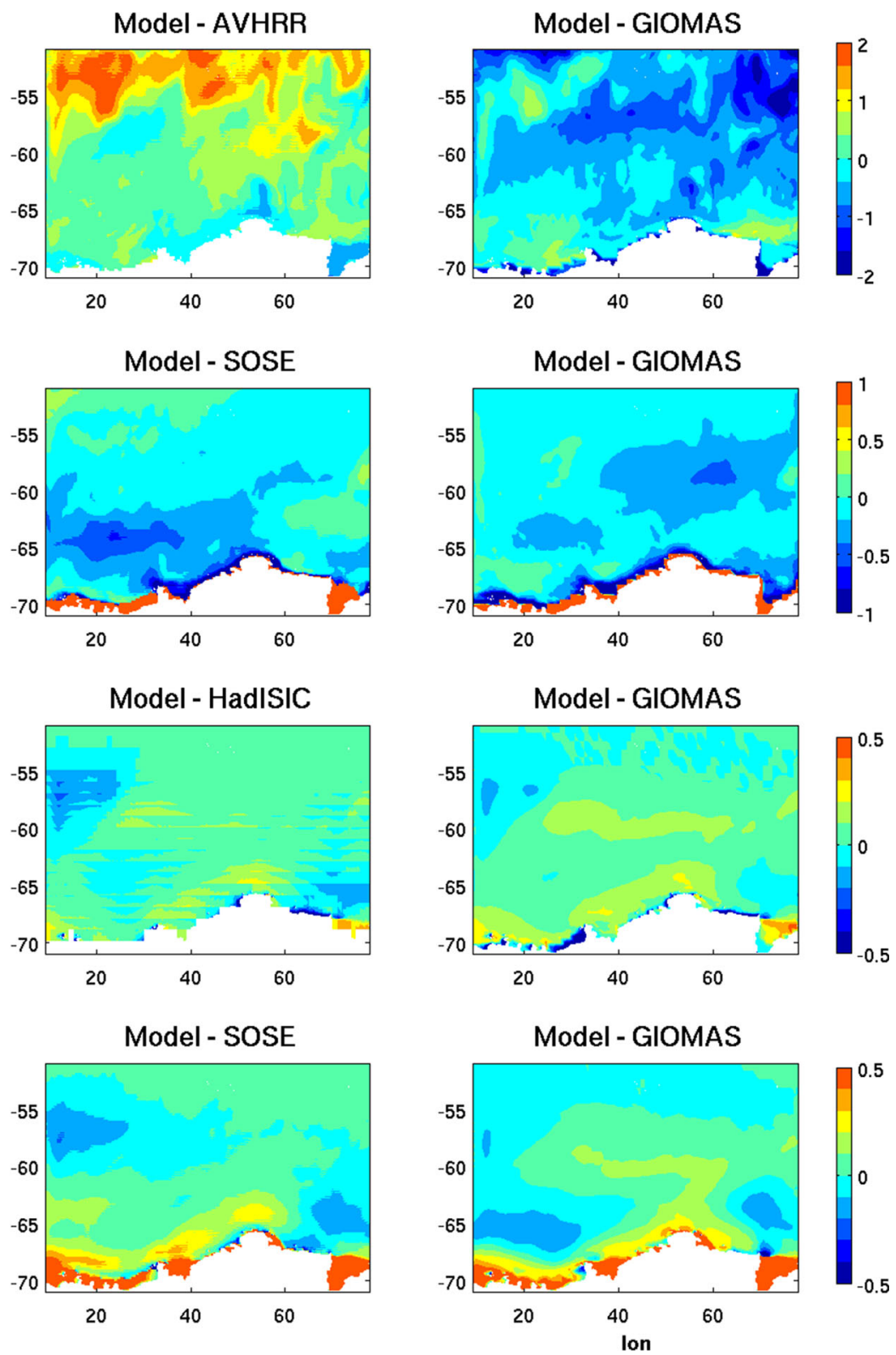

Figure 2. (Continued). using bulk formula of Large and Pond (1982). To represent the sub-grid scale mixing in vertical, we use the K-profile parametrization (KPP) scheme (Large et al. 1994). To realistically simulate sea ice in the region of study, we use built-in sea ice package (Losch et al. 2010) of the MITgcm. This package is based on viscous-plastic (VP) dynamicthermodynamic sea ice model (Zhang and Hibler 1997). To solve the non-linear momentum equation of sea ice, LSOR (line successive over relaxation) solver has been implemented. To produce reasonable values of the sea ice variables we use the open water, dry ice, wet ice, dry snow, and wet snow albedo values as $0.15,0.75,0.68,0.87$, and 0.80 , respectively. The model uses the open boundary condition on all sides. The monthly varying ocean temperature, ocean salinity, zonal and meridional current, sea ice concentration, sea ice thickness and snow thickness are prescribed on each boundary. The boundary conditions for ocean temperature, salinity, zonal and meridional current are derived from the Ocean Reanalysis System 4 (ORAS4) (Balmaseda et al. 2013). The ORAS4 is the latest ocean reanalysis product issued by the European Centre for Medium-range Weather Forecasts (ECMWF) and uses sophisticated data assimilation methodology with model bias correction. Its data is available from 1958 to present. The values 
of SIC, SIT and snow thicknesses along boundaries are extracted from the Global Ice-Ocean Modelling and Assimilation System (GIOMAS) (Zhang and Rothrock 2003). The GIOMAS consists of a global Parallel Ocean and sea Ice Model (POIM, Zhang and Rothrock 2003) with data assimilation capabilities. Satellite sea ice concentration data are assimilated in GIOMAS using the Lindsay and Zhang (2005) assimilation procedure. The procedure is based on nudging the model estimate of ice concentration towards the observed concentration in a manner that emphasizes the ice extent and minimizes the effect of observational errors in the interior of the ice pack. The GIOMAS produced global sea ice data that are available from 1979 to present. The model is initialized with World Ocean Atlas 2013 (WOA13) (Boyer et al. 2009) temperature and salinity data. The surface temperature and salinity of the model are relaxed to the ORAS4 values over a time scale of 30 days. A total of 21 years (1992-2012) of ocean sea-ice model integration is performed out of which first 5 years of data are discarded to avoid initial transients so that model reaches a stable solution.
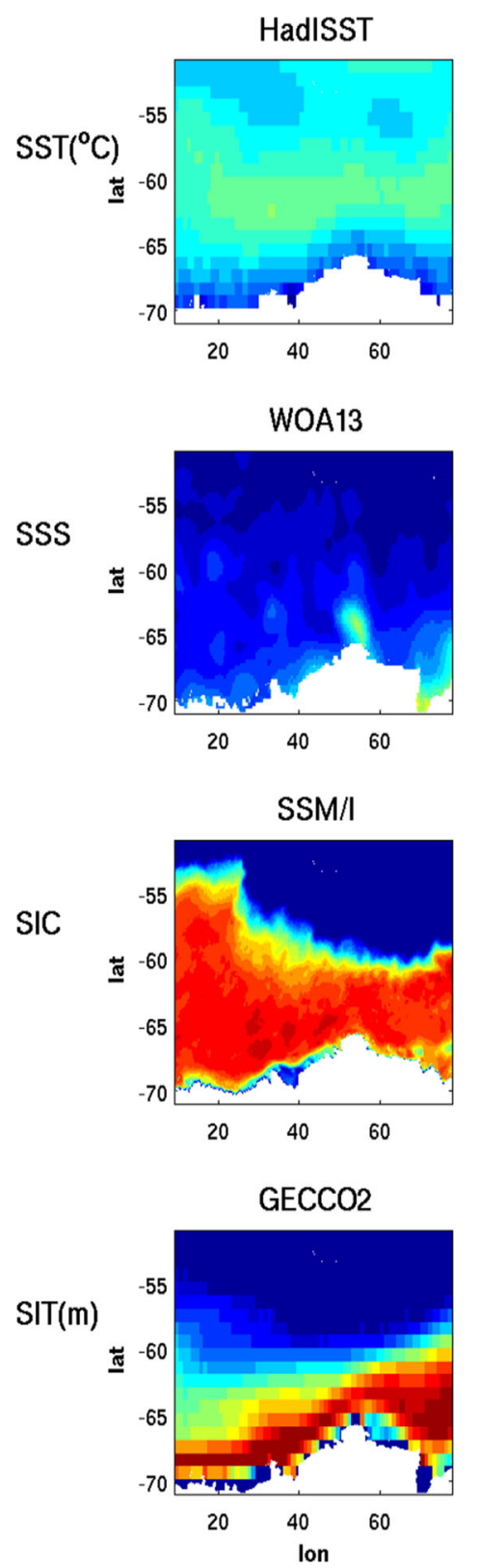
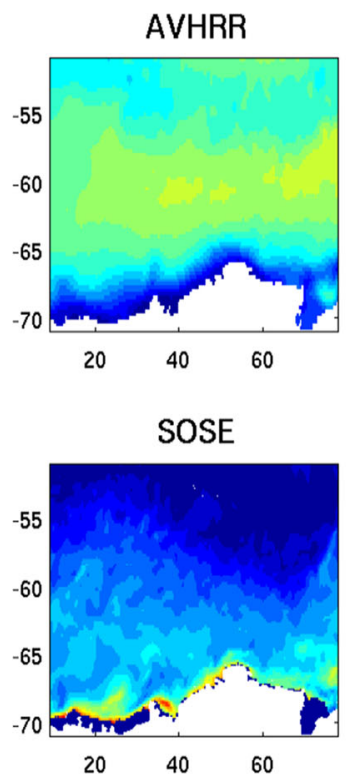

HadISIC

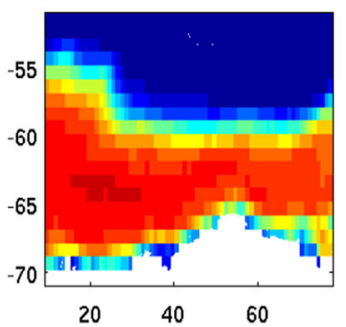

SOSE

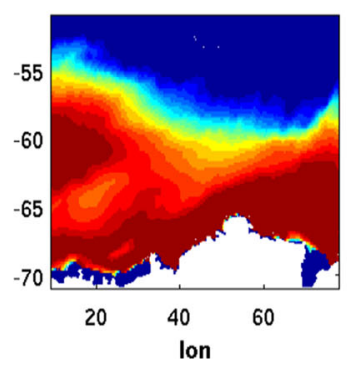

GIOMAS

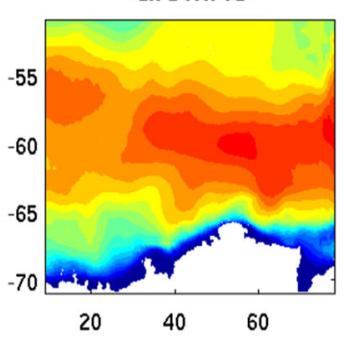

GIOMAS

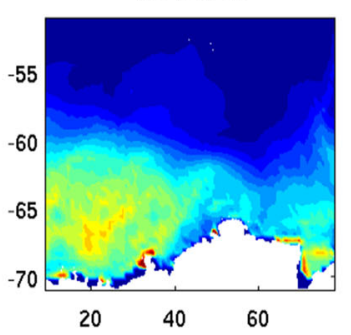

GIOMAS

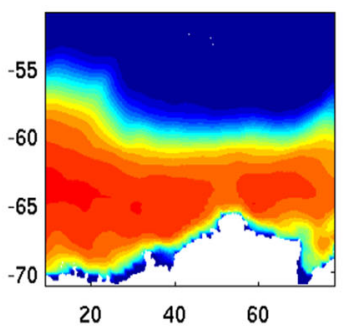

GIOMAS

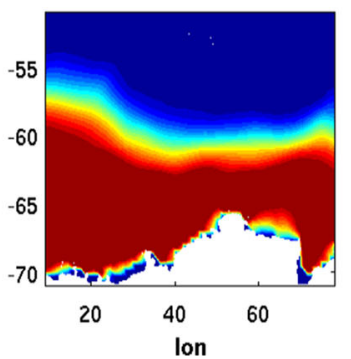

Model

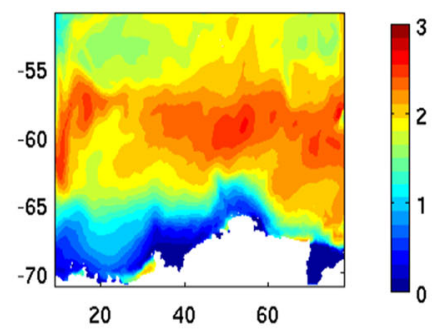

Model

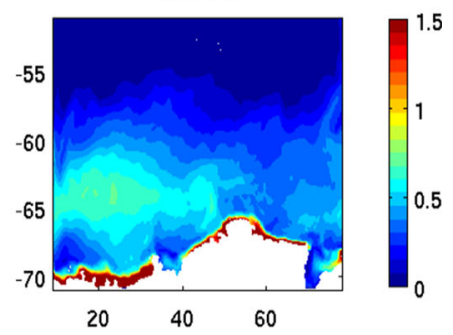

Model

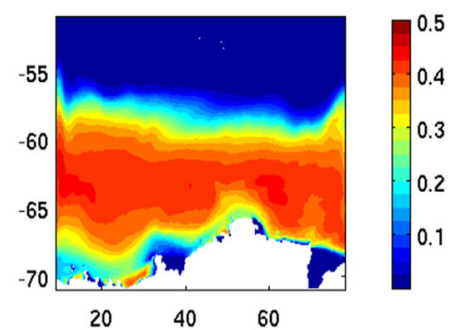

Model

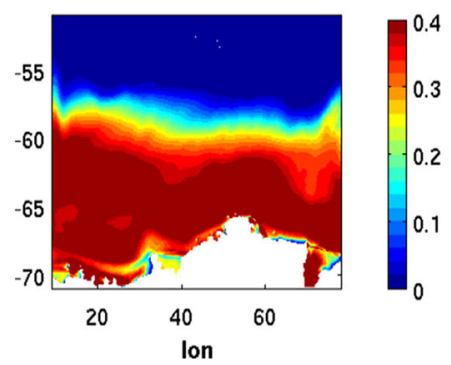

Figure 3. Spatial map of standard deviation of model SST (1st row), SSS (2nd row), SIC (3rd row) and SIT (4th row) during 1997-2012. The corresponding observations are also shown for comparison. 


\section{Results and discussion}

Using the coupled ocean sea ice model setup described above, we produce 16 years (1997-2012) of model output for analysis. To demonstrate the quality of model that simulated the ocean surface and sea ice parameters, namely, the sea surface temperature (SST), sea surface salinity (SSS), sea ice concentration (SIC) and sea ice thickness (SIT), we show their (annually averaged) climatological values in 1st, 2nd, 3rd and 4th row of figure 2(a), respectively. The corresponding observations from different products are also shown in the figure for comparison. It is clear from the figure that model captures the mean state of these variables reasonably well. For example, the correlation between model mean SST and HadISST (Rayner et al. 2003), AVHRR (Reynolds et al. 2007), GIOMAS derived mean SST is 0.96, 0.95 and 0.97, respectively. All these correlations are significant at (a)
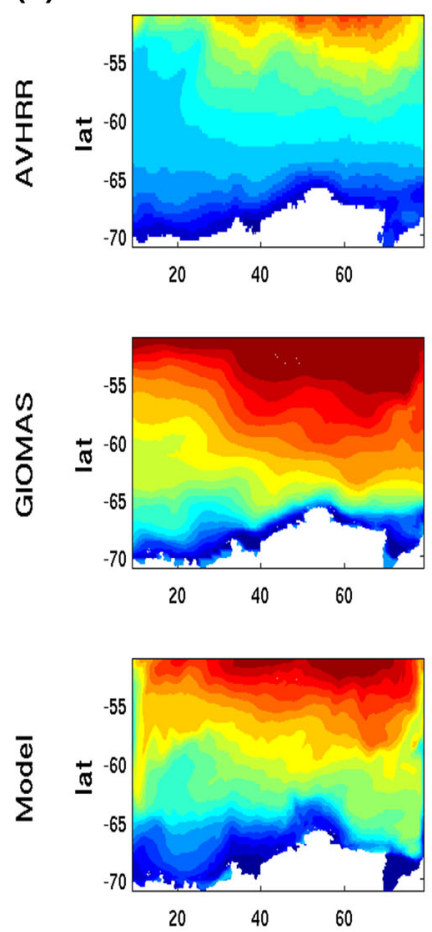

(b)
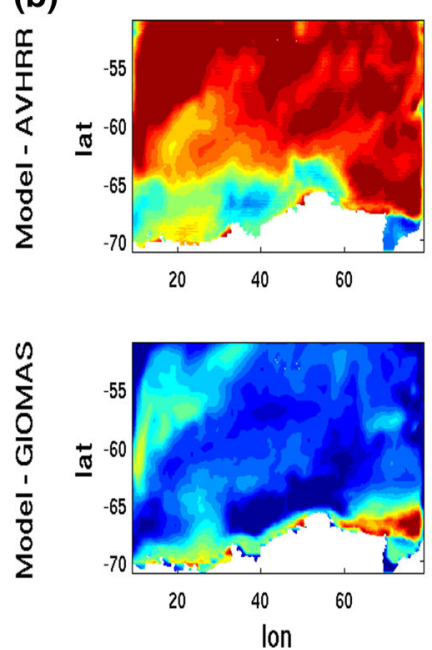

AMJ
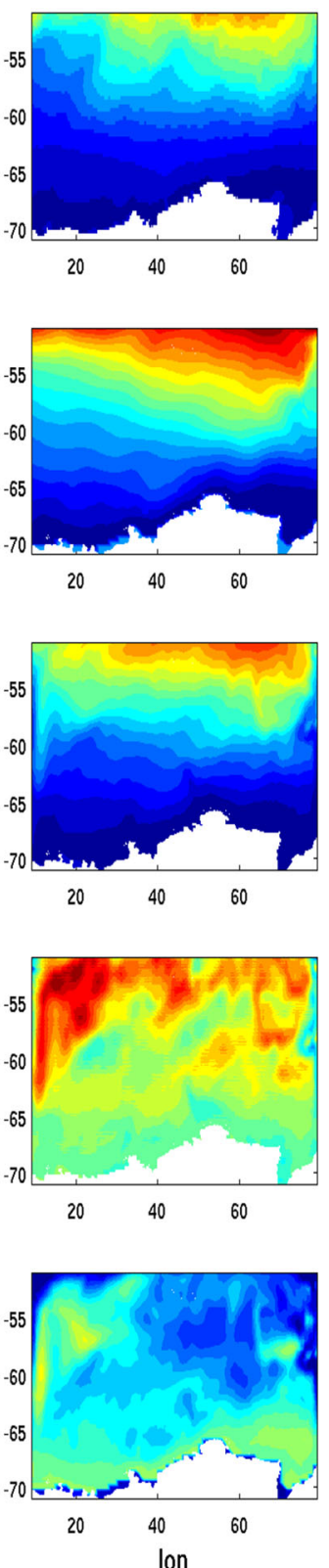

JAS
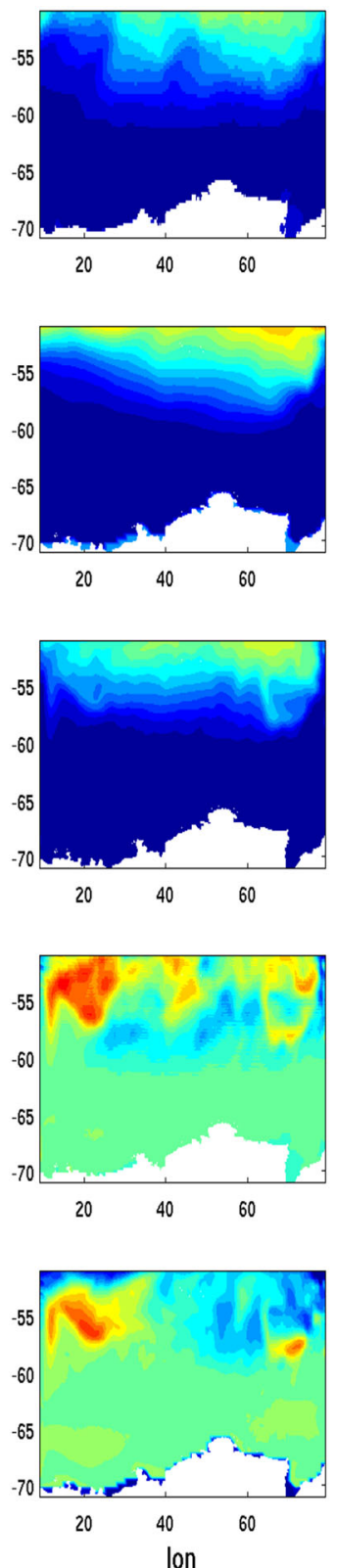

OND
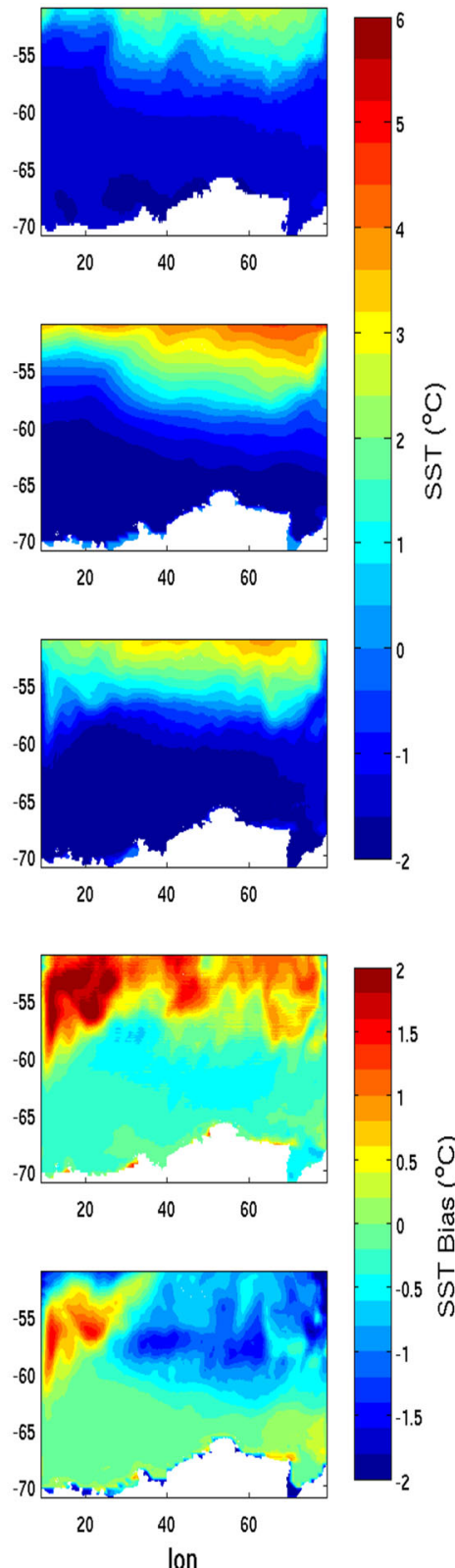

Figure 4. (Left to right) Seasonal SST map from the model (3rd row), AVHRR (1st row) and GIOMAS (2nd row) for the seasons January-February-March (JFM), April-May-June (AMJ), July-August-September (JAS), and OctoberNovember-December (OND) during 1997-2012. The 4th and 5th rows represent SST bias map with respect to AVHRR and GIOMAS, respectively. 
99.9\% level. As expected, the SST decreases as we move polewards from 51S (row 1 of figure 2a). The sea-ice regions with negative SST values are clearly distinguishable from the rest of the model domain. We also notice that in the ice-free (open ocean) regions $\left(51^{\circ}-55^{\circ} \mathrm{S}\right)$, the $\mathrm{SST}$ in the eastern part of the domain is higher as compared to western part. Similarly, the (highly significant) correlation between mean model SSS and WOA13, SOSE (Mazloff et al. 2010) and GIOMAS SSS is found to be $0.97,0.91$ and 0.95 , respectively.
Even though the model is able to get the correct spatial structure of SSS, the model derived SSS values are slightly underestimated as compared to the observed values. The high SSS values along the northwest and southeast corners are absent in the model. However, the model reproduces the high SSS values along the southwest corner. The model is also able to correctly represent the mean SIC (row 3 of figure 2a) of the region of study. The correlation coefficient between model derived mean SIC and mean SIC (a)
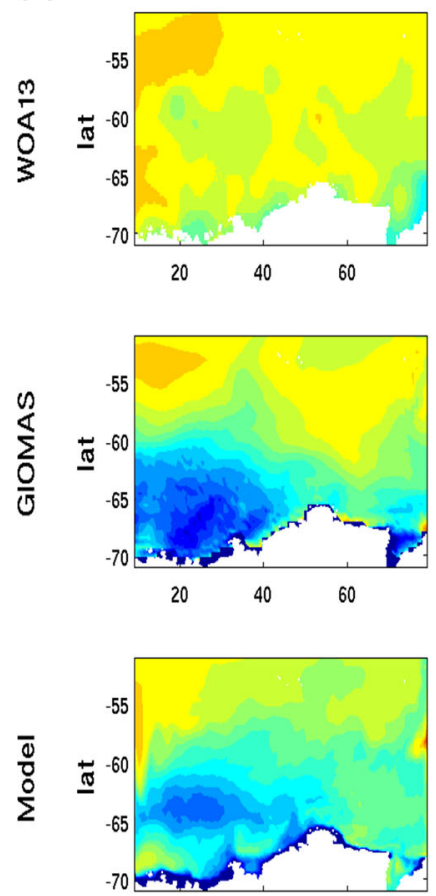

(b)
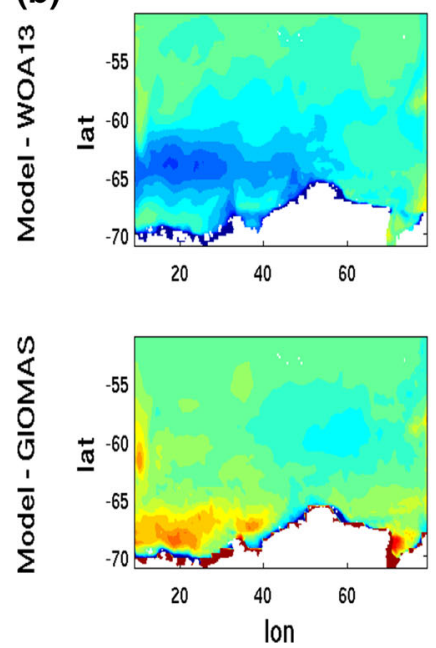

AMJ
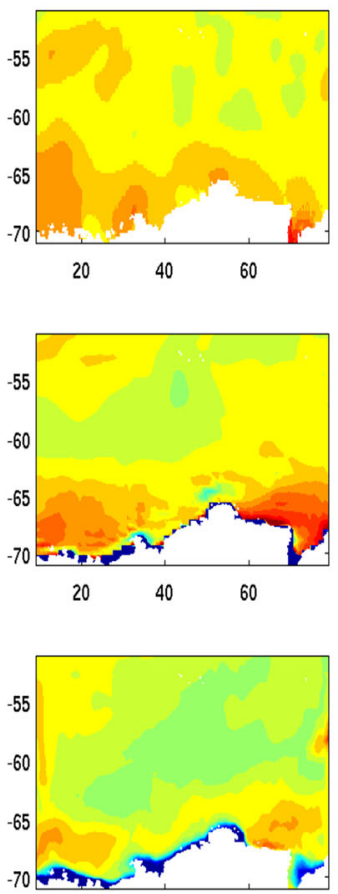

$20 \quad 40 \quad 60$
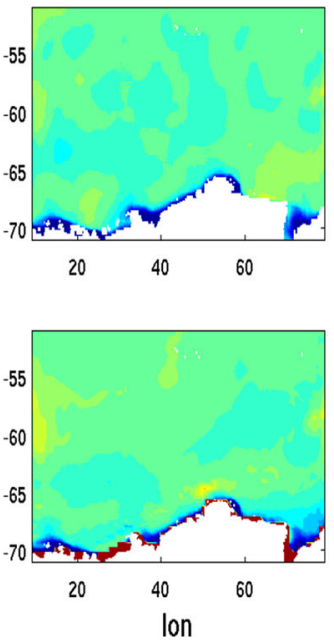

JAS
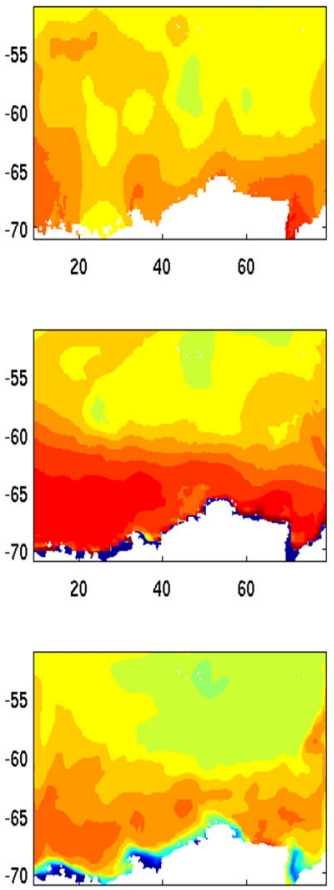

$20 \quad 40 \quad 60$
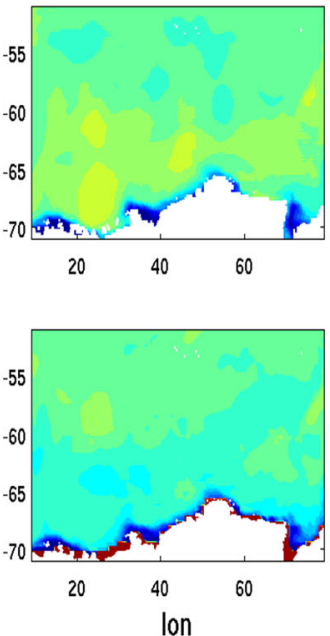

OND
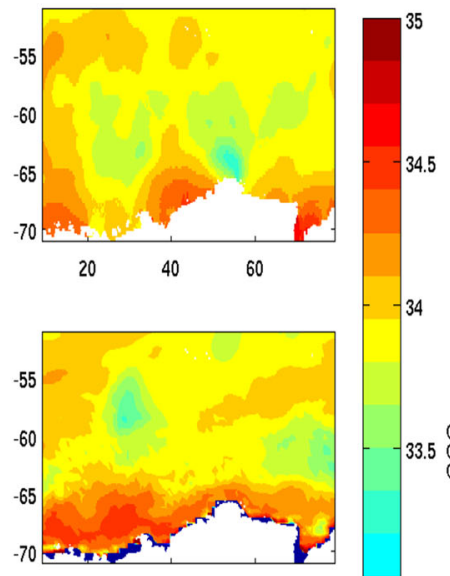

$20 \quad 40 \quad 60$

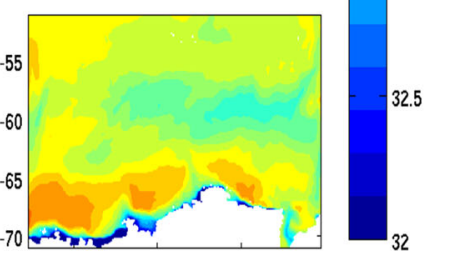

20
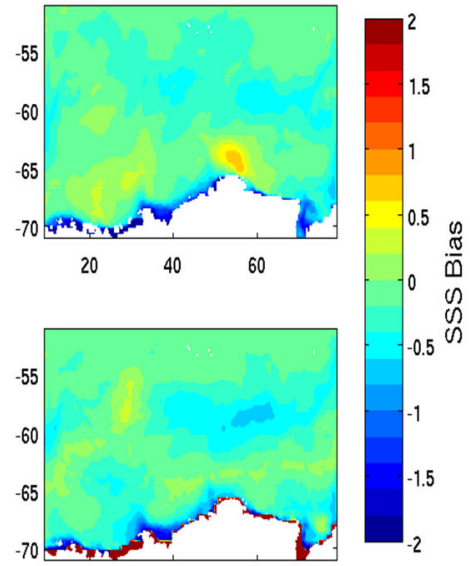

20

Figure 5. (Left to right) Comparison of seasonal SSS map from the model (3rd row), WOA13 (1st row) and GIOMAS (2nd row) for the JFM, AMJ, JAS, and OND seasons during 1997-2012. The 4th and 5th rows represent corresponding (model-observation) SSS bias map. 
derived from the SSM/I (Cavalieri et al. 1996), HadISIC (Rayner et al. 2003) and GIOMAS is found to be $0.90,0.91$ and 0.96 , respectively (each at $99.9 \%$ significant level). The SIC values near the southern boundary are slightly overestimated in the model as compared to the GIOMAS values. We also see from figure 2, row 4 that the model realistically simulates the mean SIT of the region of study. The high and low SIT regions of the domain are clearly separated. Similar to SIC, the SIT values as compared to the GECCO2
(Köhl 2015), SOSE and GIOMAS values are also slightly overestimated near the southern boundary. The low values of SST, air temperature, and incoming solar radiation near the polar regions help in increasing the SIC and SIT at higher latitudes.

We also compute bias between mean states of model and observation to gauge the quality of model solution. The bias (model-observation) maps for SST, SSS, SIC and SIT are shown in 1st, $2 \mathrm{nd}, 3 \mathrm{rd}$ and 4 th rows of figure $2(\mathrm{~b})$, respectively. (a)
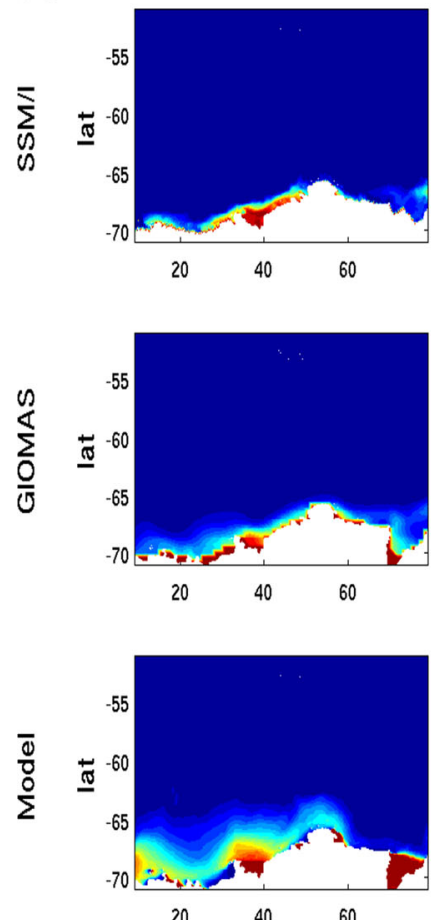

(b)
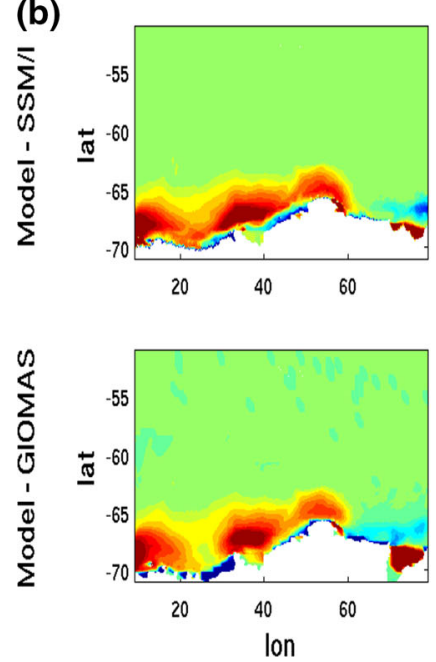

AMJ
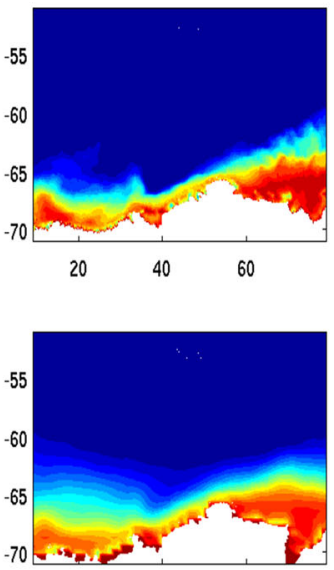

60

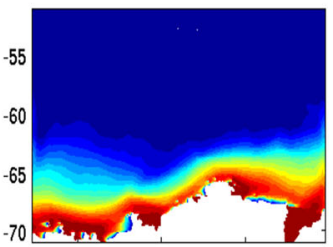

$20 \quad 40 \quad 60$
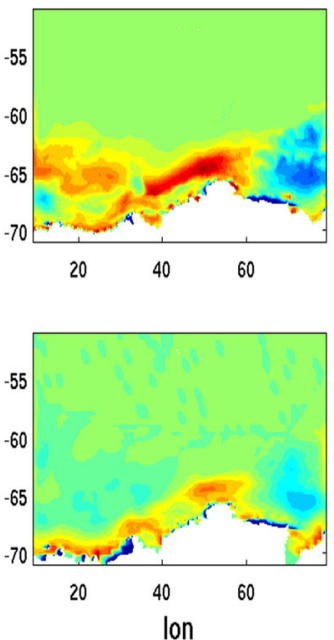

JAS
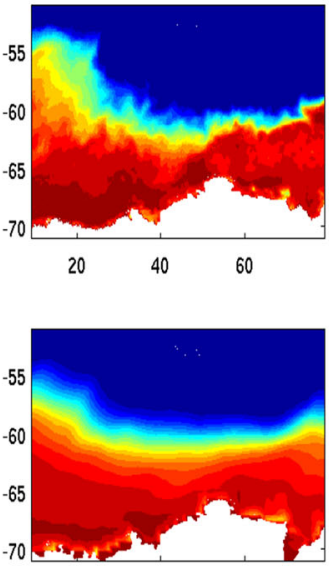

60

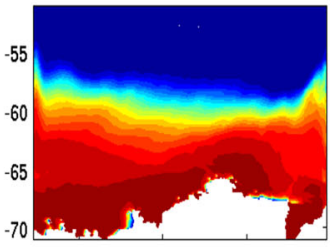

$20 \quad 40 \quad 60$
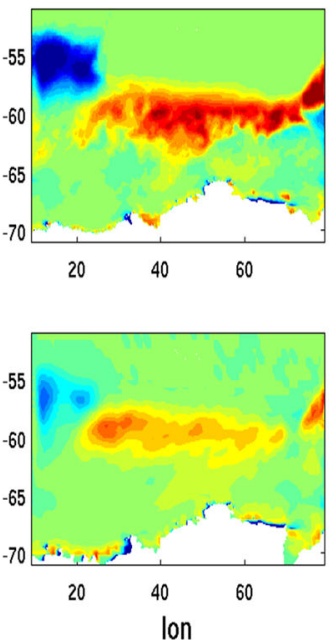

OND
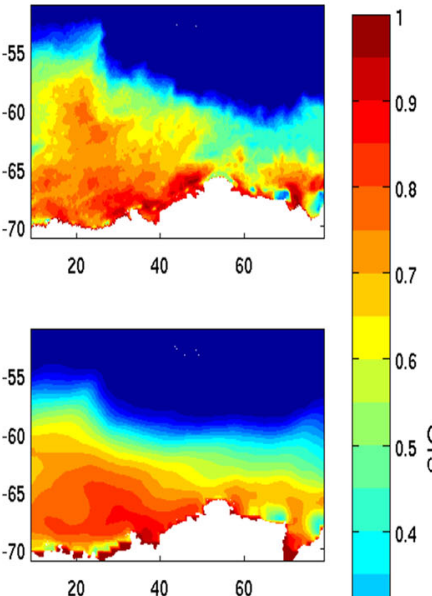

$0.5 \frac{U}{0}$
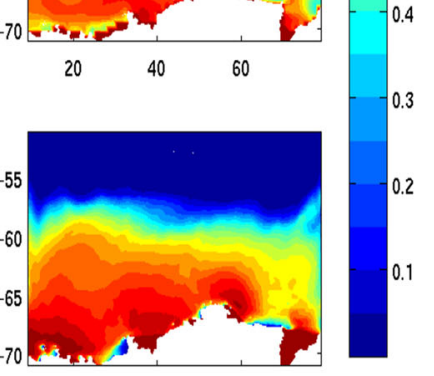

$20 \quad 40 \quad 60$
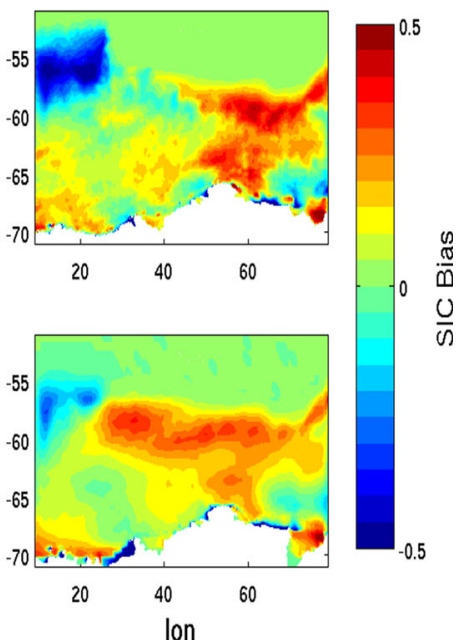

Figure 6. (Left to right) Comparison of seasonal SIC map from the model (3rd row), SSM/I (2nd row) and GIOMAS (1st row) for the JFM, AMJ, JAS, and OND seasons during 1997-2012. The 4th and 5th rows represent corresponding (model-observation) SIC bias map. 
It is clear from the 1st row of figure 2(b) that model-HadISST and model-AVHRR SST bias is very low in the sea-ice regions confirming the quality of model output. However, the model slightly overestimates the mean SST in the open ocean regions (north of $55^{\circ} \mathrm{S}$ ) as compared to HadISST and AVHRR SST. On the other hand, the bias map with respect to GIOMAS SST suggests that model SST values are slightly underestimated in the central and northeastern parts of the domain. The SSS bias (2nd row), in general, is also small in the entire region except along the southern coasts. Similarly, the mean SIC and SIT bias with respect to observations is very small in the entire model domain barring few places. The low values in the bias map of the all the variables, therefore, demonstrate the robustness of the model solution against the compared observations.

To assess the spatio-temporal variability of model simulated SST, SSS, SIC and SIT, the standard deviation of these variables are plotted in figure 3. It is clear from the figure that the model very well captures the space-time variability of these variables. It is interesting to notice that while most of the SST variability $(>1.5 \mathrm{C})$ is seen between $55^{\circ}$ and $65^{\circ} \mathrm{S}$ (intermediate portion of the model domain), the SSS on the other hand shows prominent variability in the southern domain (south of $60^{\circ} \mathrm{S}$ ). This suggests that the SSS of the open ocean does not change much. On the other hand, the sea-ice has a lot of influence in changing the SSS of the region. In contrast to this, the SST of the sea-ice region shows low variability, and the model is also able to clearly demonstrate this feature. In case of SIC and SIT, we found high spatio-temporal variability in the sea-ice regions (between $60^{\circ}$ and $67^{\circ} \mathrm{S}$ ). The standard deviation of the SIC is found to be low along the southern coastal regions. This suggests that the sea ice concentration along these regions (which are ice covered almost throughout the year) varies very little. The standard deviation of model SIT is slightly underestimated.

To further examine the model simulated SST, SSS and SIC the seasonal maps of these variables are plotted against GIOMAS. The seasons chosen for this purpose are Jan-Feb-Mar (JFM), AprMay-Jun (AMJ), Jul-Aug-Sept (JAS), and OctNov-Dec (OND). In figure 4, the seasonal plot of model derived SST (3rd row) is shown and a comparison is made with AVHRR SST (1st row) and GIOMAS SST (2nd row). The difference between model and AVHRR SST is shown as bias map in 4th row, whereas the difference between model and GIOMAS SST is shown as bias map in 5th row. We see from figure that the seasonal variability exhibited by the model matches very well with the AVHRR and GIOMAS derived SST. The SST
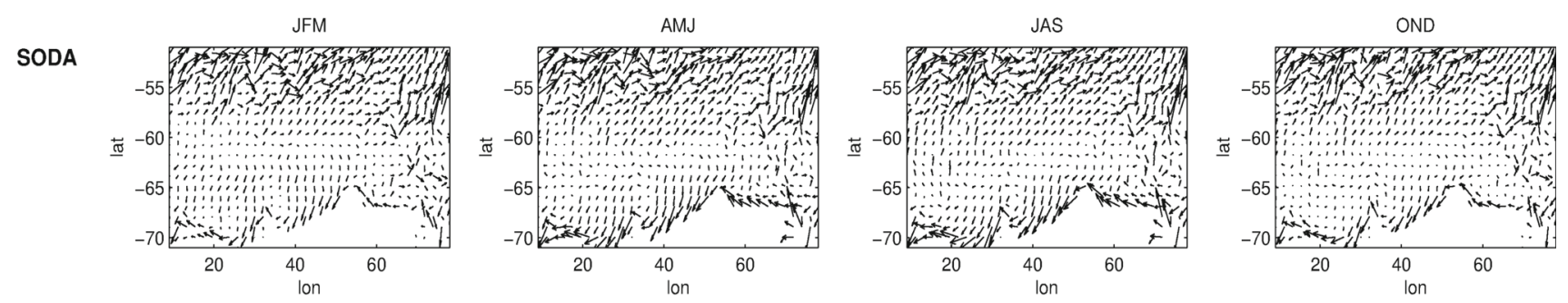

GIOMAS
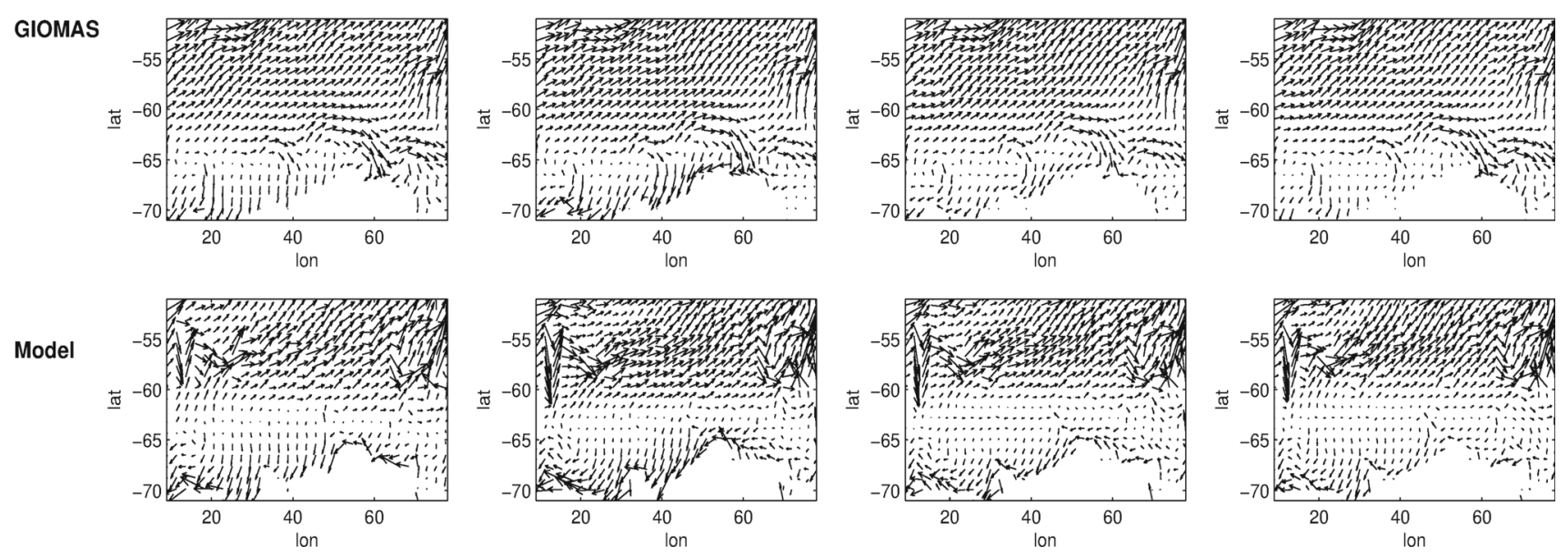

Figure 7. Seasonal variability of the ocean surface current from model and its comparison with corresponding SODA and GIOMAS observations. 
values are highest during the summer/melting season (JFM). The JFM SST values (figure 4, column 1) are positive throughout the region except at the higher latitudes near the southern boundary where we notice negative SST values. The SST decreases almost monotonically from north to south of the domain. Moreover, the eastern part of the domain shows higher SST than western part. The Model-AVHRR (Model-GIOMAS) bias map for the JFM season with dominantly positive (negative) values suggests that model slightly overestimates (underestimates) the SST in nearly the entire domain. During the AMJ season, the SST decreases rapidly as compared to JFM. The values south of $60^{\circ} \mathrm{S}$ are negative. The SST bias is also low in AMJ season. During the JAS (winter/freezing) season, the SST of the region is lowest. It is also clear from figure 4 , column 3 (4th and 5th rows) that in the JAS season, the SST bias is nearly absent in the sea-ice regions indicating that the model very well captures the SST of the region. During the post-winter OND season, we see an increase in the SST as compared to JAS season. The model slightly overestimates the SST in the northwest region (4th and 5th rows of figure 4, column 4) compared to AVHRR and GIOMAS. On the other hand, the model derived SST of other regions north of $60^{\circ} \mathrm{S}$ is slightly overestimated (underestimated) compared to AVHRR (GIOMAS).

The evaporation, precipitation and formation of sea ice are the major factors for variation of sea surface salinity. Along with temperature, salinity is used for the determination of water density and thus is intimately linked to the global ocean circulation. The seasonal variability of the surface salinity of the Antarctic sea ice region influences the mixed layer depth variability and biological productivity of the region. The SSS variability of the region, on the other hand, gets largely influenced by the freshwater flux accompanied with the sea ice formation and melting. We show in figure 5, the seasonal SSS variability from the model (3rd row) and compare it with the WOA13 (1st row) and GIOMAS (2nd
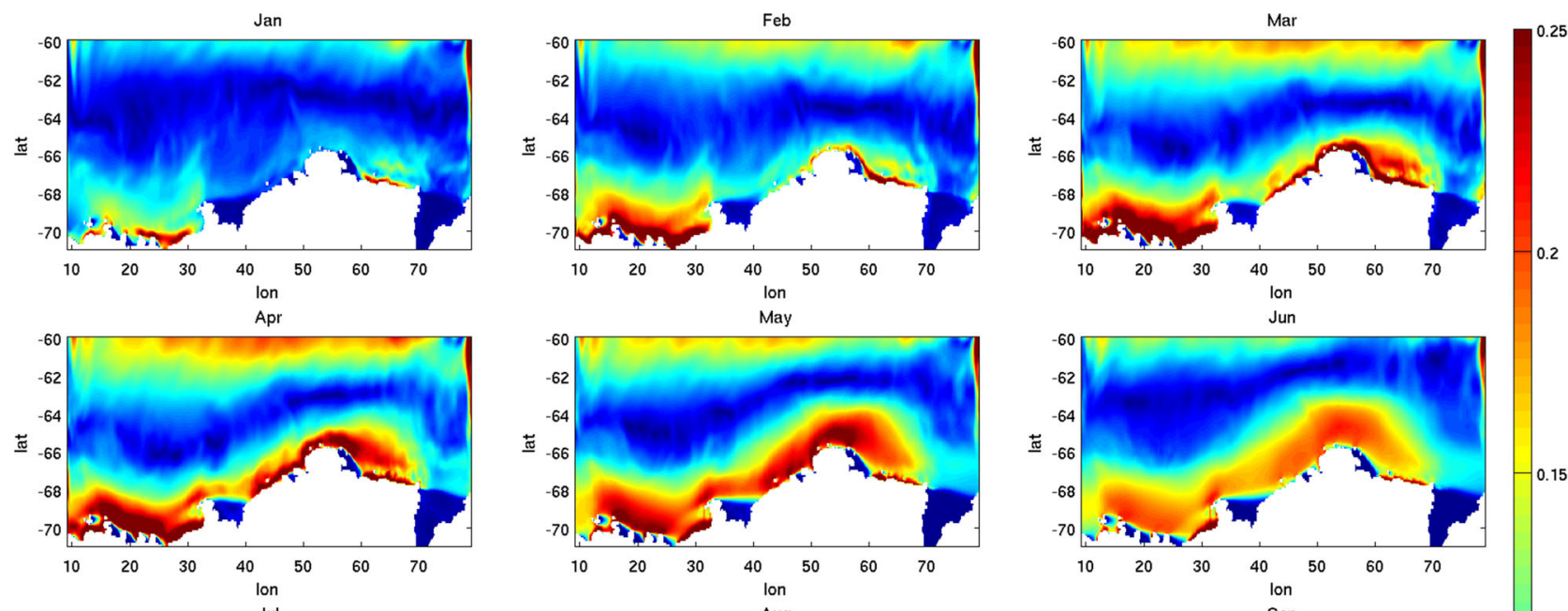

Jun
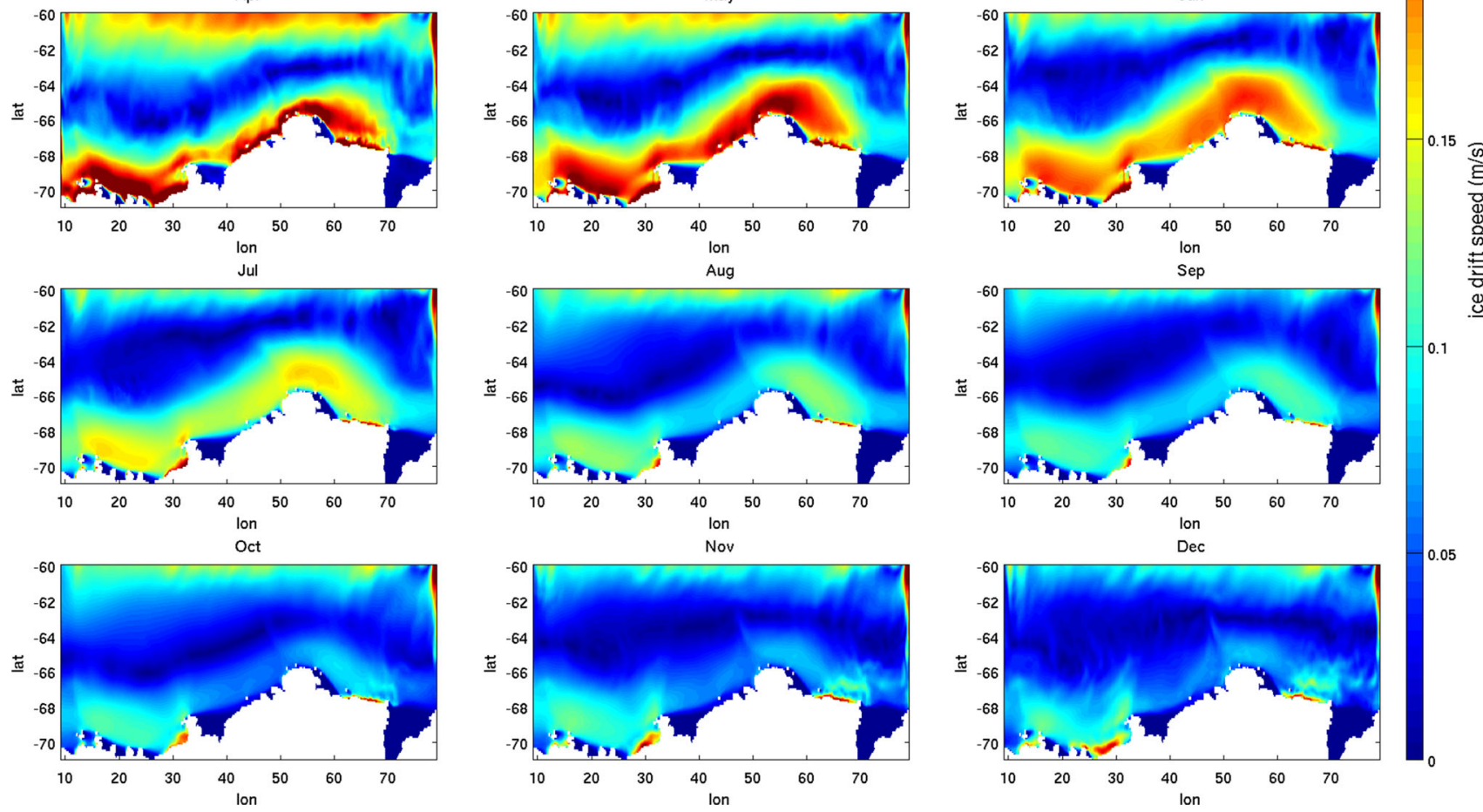

Figure 8. Monthly spatial variation of sea ice drift speed over $\left(9^{\circ}-78^{\circ} \mathrm{E} ; 60^{\circ}-71^{\circ} \mathrm{S}\right)$ during $1997-2012$. 
row) derived SSS. We notice that north of $55^{\circ} \mathrm{S}$, there is not much seasonal variation of SSS. Most of the SSS variability occurs only in the sea ice region south of $60^{\circ} \mathrm{S}$ largely due to the melting and freezing of sea ice. During the summer (JFM) season, very low SSS is observed in the sea ice regions (south of $60^{\circ} \mathrm{S}$ ) due to melting of sea ice. The southwest region of domain exhibits particularly low SSS compared to other parts of the domain. During the autumn (AMJ) and spring season (OND), we see intermediate SSS in the range of $34 \pm 0.5$ in the sea ice regions. The highest SSS is found during JAS season as a result of brine ejection due to sea ice formation (freezing). We also see from 4 th and 5 th rows of figure 5 that the SSS bias between model and observation is very low in all the seasons, except during JFM along the southwest corner.
This suggests that the seasonal variability of the SSS is very well reproduced by the model.

To investigate the seasonal SIC variability, we show its map in figure 6 . The model derived SIC values are shown in 3rd row and their comparison is made with the SSM/I (1st row) and GIOMAS (2nd row) derived SIC values. It is clear from the figure that the model very well simulates the large seasonal variability exhibited by the SIC. For example, during the summer (JFM) season, we observe very low (almost zero) sea ice concentration as a result of sea ice melting. The SIC gradually increases all through the autumn (AMJ) and becomes highest (nearly 1) during the winter (JAS) season as a result of freezing of sea ice. The SIC then gradually starts to decrease during spring (OND) season. From the bias maps in
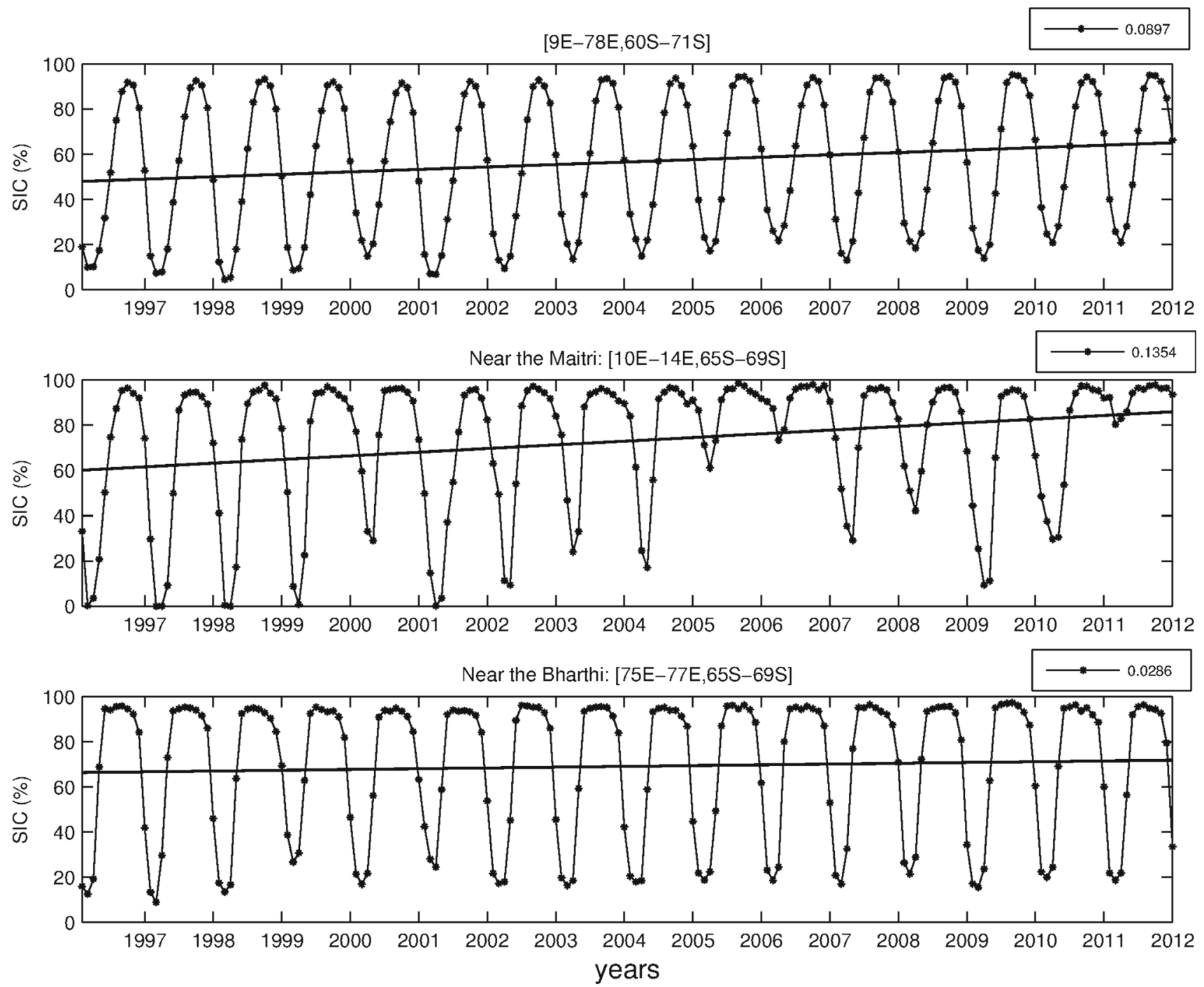

Figure 9. Monthly time series of the SIC area averaged over the region (first row) $\left(9^{\circ}-78^{\circ} \mathrm{E} ; 60^{\circ}-71^{\circ} \mathrm{S}\right)$, (second row) $\left(10^{\circ}-14^{\circ} \mathrm{E}, 65^{\circ}-69^{\circ} \mathrm{S}\right)$ near Maitri, and (third row) $\left(75^{\circ}-77^{\circ} \mathrm{E} ; 65^{\circ}-69^{\circ} \mathrm{S}\right)$ near Bharati. The solid lines represent the best-fit straight lines used to compute the trend. 
4 th and 5th rows of figure 6 , we notice that the bias in general is low in all the regions except at few places. The bias between model and SSM/I as well as between model and GIOMAS derived SIC is somewhat higher in the OND season, however, model SIC values are slightly overestimated in the middle and eastern parts of the domain and underestimated in the northwestern side of domain.

To demonstrate the quality of model simulated ocean surface current, we plot in figure 7, the seasonally varying surface current (third row) and compare it with the SODA (first row) and GIOMAS (second row) currents. The model very well captures the circulation of the region. In the sea ice free regions (north of $60^{\circ} \mathrm{S}$ ), we notice dominantly zonal strong west to east Antarctica Circumpolar Current (ACC) in all the seasons. In contrast to this, in the sea ice region south of $65^{\circ} \mathrm{S}$, we observe dominantly meridional poleward flow. During the AMJ season, the currents in the sea ice region are the strongest with a slightly clockwise direction of flow. On the other hand, the weakest currents in sea ice region are noticed during the OND. However, not very prominent seasonal changes in the surface current are observed in the region of study during the period of simulation.

The drift of the sea ice is one of the important features of the SO packed ice. The nature of the ice drift determines the sea ice thickness distribution and helps in studying the degree of interaction between the ocean and atmosphere. To examine the variability in the sea ice drift speed throughout the year, we plot in figure 8 the monthly drift speed map for the sea ice region $\left(9^{\circ}\right.$ $\left.78^{\circ} \mathrm{E} ; 60^{\circ}-71^{\circ} \mathrm{S}\right)$. We find that the sea ice drift speed of the region varies significantly during the
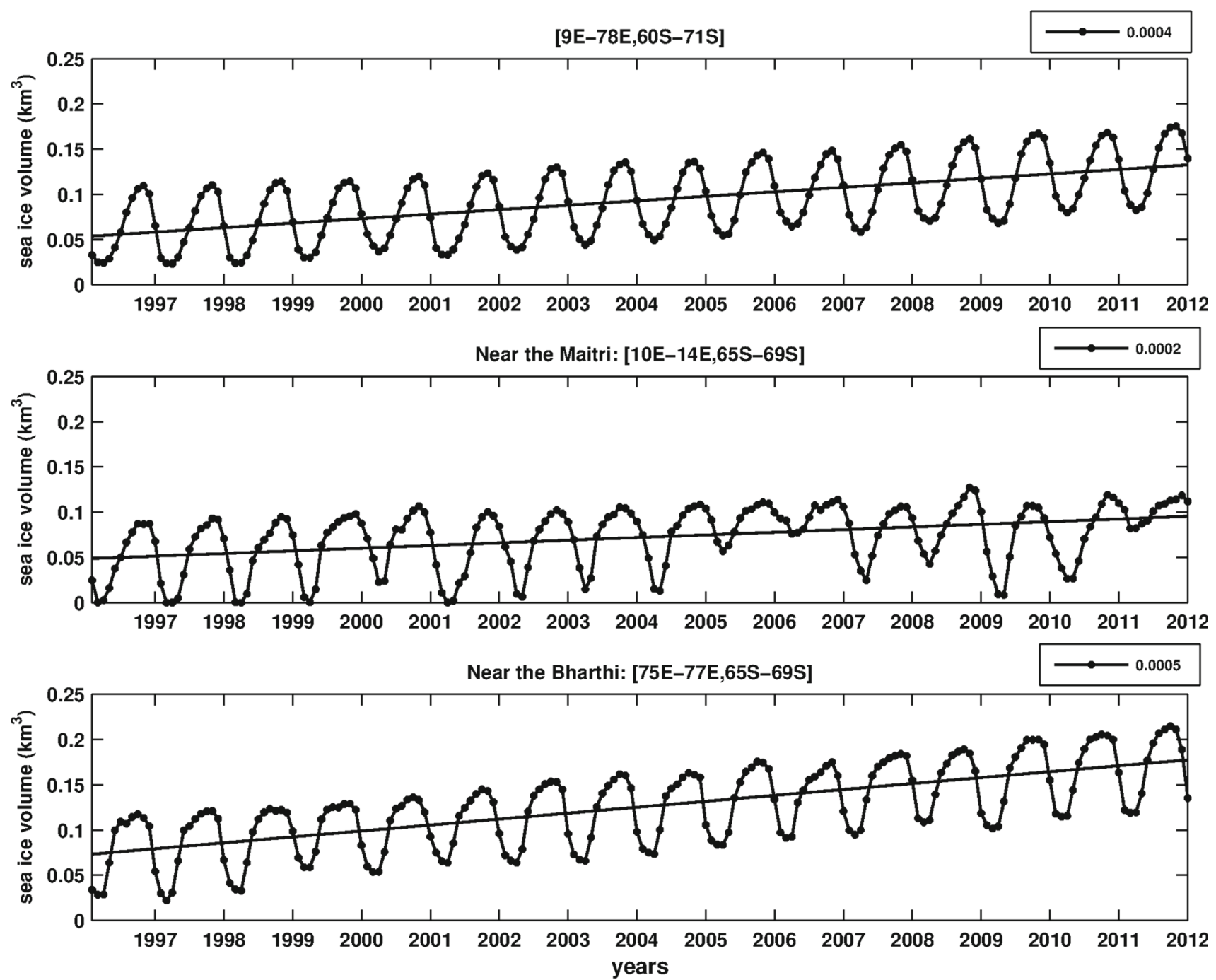

Figure 10. Monthly time series of the sea ice volume area averaged over the region (first row) $\left(9^{\circ}-78^{\circ} \mathrm{E} ; 60^{\circ}-71^{\circ} \mathrm{S}\right),(\mathrm{second}$ row) $\left(10^{\circ}-14^{\circ} \mathrm{E} ; 65^{\circ}-69^{\circ} \mathrm{S}\right)$ near Maitri, and (third row) $\left(75^{\circ}-77^{\circ} \mathrm{E} ; 65^{\circ}-69^{\circ} \mathrm{S}\right)$ near Bharati. The trend is shown by the best-fit solid lines. 
year. The variation is, however, seen only along the northern and southern parts of the domain and remains nearly absent in the intermediate portion. The drift speed starts to increase from February onwards, becomes maximum during April-May and then gradually decreases. It becomes very small from September onwards due to the presence of predominantly packed (frozen) sea ice.

To further examine the SIC variability in the region of study, we show its monthly time series area averaged over the region $\left(9^{\circ}-78^{\circ} \mathrm{E} ; 60^{\circ}-\right.$ $71^{\circ} \mathrm{S}$ ) for the period $1997-2012$ in figure 9 (upper panel). The SIC time series shows nearly periodic nature. The minimum SIC is obtained during February-March and the maximum during August-September. The June and December months show intermediate SIC values. We compute trend of the SIC time series and found it to be 0.09. Thus the SIC of the region increases at the rate of nearly $0.09 \%$ per month (i.e., approximately $1 \%$ per year). We made a similar analysis around Maitri and Bharati Indian Antarctic stations. The SIC time series area averaged over the region $\left(10^{\circ}-\right.$ $\left.14^{\circ} \mathrm{E} ; 65^{\circ}-69^{\circ} \mathrm{S}\right)$ around Maitri station is shown in figure 9 (middle panel). We notice from the figure that the year 2005-2007 and 2011-2013 show particularly high SIC values. The SIC of the region increases at a rate of $0.14 \%$ per month, which is higher than the SIC growth rate computed over the bigger sea ice model domain. On the other hand, a similar analysis carried out over the region $\left(75^{\circ}-\right.$ $77^{\circ} \mathrm{E} ; 65^{\circ}-69^{\circ} \mathrm{S}$ ) around Bharati station (figure 9, lower panel) suggests that the SIC of this region increases at a smaller rate of $0.03 \%$ per month. Thus the rate of SIC increase near Maitri station is approximately five times to that near Bharati station.

To put the results into perspective, we also compute sea ice volume $\left(\right.$ in $\mathrm{km}^{3}$ ) of the region. The monthly sea ice volume time series area averaged over the region $\left(9^{\circ}-78^{\circ} \mathrm{E} ; 60^{\circ}-71^{\circ} \mathrm{S}\right)$ is shown in figure 10 (upper panel) for the duration of study. It shows periodic variations similar to that of SIC. We find that the sea ice volume of the region increases at the rate of $0.0004 \mathrm{~km}^{3}$ per month (i.e., approximately $0.005 \mathrm{~km}^{3}$ per year). A similar analysis made for the regions surrounding Maitri (figure 10, middle panel) and Bharati (figure 10, lower panel) Indian Antarctic stations illustrate that the sea ice volume shows positive trend of 0.0002 and $0.0005 \mathrm{~km}^{3}$ per month, respectively. Thus, even though the SIC of Bharati region is increasing at a significantly lower rate as compared to Maitri region, the increase in the sea ice volume presents exactly the opposite picture. More sea ice is getting accumulated around Bharati region as compared to Maitri region over the period of study.

\section{Conclusions}

We use the MITgcm to perform a high-resolution (6-10 km) coupled ocean sea-ice modelling in the SO region. The model domain is chosen around $\left(9^{\circ}-78^{\circ} \mathrm{E} ; 51^{\circ}-71^{\circ} \mathrm{S}\right)$ in the SO which covers both Maitri and Bharati Indian Antarctic Stations. We demonstrate realistic simulation of the SST, SSS, surface currents, SIC and SIT for the period 19972012. We examine mean and seasonal variability of these variables and also compare them with the available observations in the region of study. We find that the SIC of the model domain is increasing at a rate of nearly $1 \%$ per year. The SIC near Maitri region is increasing at a much faster rate $(1.7 \%$ per year) compared to Bharati region ( $0.4 \%$ per year). We also estimate variability of the drift of sea-ice over the period of simulation and found it to be significantly varying during the year. The maximum drift speed is seen during April-May. We found that the sea ice volume of the region increases at the rate of $0.0004 \mathrm{~km}^{3}$ per month (nearly $0.005 \mathrm{~km}^{3}$ per year). It is also found that the sea ice volume of Maitri and Bharati regions increases at a rate of 0.0002 and $0.0005 \mathrm{~km}^{3}$ per month, respectively. Thus the tendency of more sea ice getting accumulated around Bharati station is higher as compared to Maitri station. We hope that the high-resolution (in space and time) ocean sea ice model data shall be useful for researchers interested in understanding hydrography, circulation, and sea ice dynamics of the region.

\section{Acknowledgements}

The authors thank the anonymous reviewer and editor for the constructive comments that led to improvement of the manuscript. AK is thankful to ISRO for providing Junior Research Fellowship. SD is thankful to the NCAOR/ISRO/DST for financial assistance in the form of research project. Thanks are also due to the NCEP/NCAR, ORAS4, HadISST, AVHRR, SOSE, GECCO2, SSM/I, and GIOMAS communities for making their data freely available for research purpose. 


\section{References}

Bader J, Flugge M, Kvamsto N G, Mesquita M D and Voigt A 2013 Atmospheric winter response to a projected future Antarctic sea-ice reduction: A dynamical analysis; Clim. Dyn. 40 2707-2718.

Balmaseda M A, Mogensen K and Weaver A T 2013 Evaluation of the ECMWF ocean reanalysis system ORAS4; Quart. J. Roy. Meteorol. Soc. 139 1132-1161.

Bitz C M, Gent P R, Woodgate R A, Holland M M and Lindsay R 2006 The influence of sea ice on ocean heat uptake in response to increasing $\mathrm{CO}_{2} ;$ J. Climate 19 2437-2450.

Boyer T P, Antonov J I, Baranova O K, Garcia H E, Johnson D R, Locarnini R A, Mishonov A V, Seidov D, Smolyar I V and Zweng M M 2009 World Ocean Database 2009, Chap. 1: Introduction, NOAA Atlas NESDIS 66 (ed.) Levitus S, U.S. Gov. Printing Office 216.

Campin J M, Marshall J and Ferreira D 2008 Sea ice-ocean coupling using a rescaled vertical coordinate $\mathrm{z}$; Ocean Model. 24 1-4.

Cavalieri D J, Parkinson C L, Gloersen P and Zwally $\mathrm{H}$ J 1996 Sea ice concentrations from Nimbus-7 SMMR and DMSP SSM/I-SSMIS passive microwave data, NASA National Snow and Ice Data Center Distributed Active Archive Center at Boulder, Colorado USA, doi: 10.5067/ 8GQ8LZQVL0VL.

Cavalieri D J, Parkinson C L and Vinnikov K Y 2003 30-year satellite record reveals contrasting Arctic and Antarctic decadal sea ice variability; Geophys. Res. Lett. 301970 , doi: 10.1029/2003GL018031.

Fichefet T, Goosse H and Maqueda M A M 2003 A hind cast simulation of Arctic and Antarctic sea ice variability, 1955-2001; Polar Res. 22 91-98.

Fichefet T, Tartinville B and Goosse H 2003 Antarctic sea ice variability during 1958-1999: A simulation with a global ice-ocean model; J. Geophys. Res. Oceans 108(C3) 3102, doi: 10.1029/2001JC001148.

Fletcher J O 1969 Ice extent in the southern oceans and its relation to world climate; J. Glaciol. 15 417-427.

Grumbine R W 1994 A sea-ice albedo experiment with the NMC medium range forecast model; Wea. Forecasting $\mathbf{9}$ $453-456$.

Hellmer H H 2004 Impact of Antarctic ice shelf basal melting on sea ice and deep ocean properties; Geophys. Res. Lett. 31 L10307, doi: 10.1029/2004GL019506.

Holland P R, Bruneau N, Enright C, Losch M, Kurtz N T and Kwok R 2014 Modeled trends in Antarctic sea ice thickness; J. Climate 27 3784-3801.

Hunke E C, Lipscomb W H and Turner A K 2010 Sea-ice models for climate study: Retrospective and new directions; J. Glaciol. 56 1162-1172.

Jackett D R and Mcdougall T J 1995 Minimal adjustment of hydrographic profiles to achieve static stability; J. Atmos. Ocean. Tech. 12 381-389.

Kalnay E, Kanamitsu M, Kistler R, Collins W, Deaven D, Gandin L, Iredell M, Saha S, White G, Woollen J and Zhu Y 1996 The NCEP/NCAR 40-year reanalysis project; Bull. Am. Meteor. Soc. 77 437-471.

Kidston J, Taschetto A S, Thompson D W J and England M H 2011 The influence of Southern Hemisphere sea-ice extent on the latitude of the midlatitude jet stream; Geophys. Res. Lett. 38 L15804, doi: 10.1029/2011GL048056.
Köhl A 2015 Evaluation of the $\mathrm{GECCO}_{2}$ ocean synthesis: Transports of volume, heat and freshwater in the Atlantic; Quart. J. Roy. Meterol. Soc. 141(686) 166-181.

Kurtz N T and Markus T 2012 Satellite observations of Antarctic sea ice thickness and volume; J. Geophys. Res. 117 C08025, doi: 10.1029/2012JC008141.

Kusahara K, Hasumi H and Williams G D 2011 Dense shelf water formation and brine-driven circulation in the Adelie and George V Land region; Ocean Model. 37122 138.

Large W G, McWilliams J C and Doney S C 1994 Oceanic vertical mixing: A review and a model with a nonlocal boundary layer parameterization; Rev. Geophys. 32 363-403.

Large W G and Pond S 1982 Sensible and latent heat flux measurements over the ocean; J. Phys. Oceanogr. 12 464-482.

Lemke P, Ren J, Alley R B, Allison I, Carrasco J, Flato G, Fujii Y, Kaser G, Mote P, Thomas R H and Zhang T 2007 Observations: Changes in snow, ice and frozen ground; In: Climate Change 200\%: The Physical Science Basis, Contribution of Working Group I to the Fourth Assessment Report of the Intergovernmental Panel on Climate Change, Cambridge University Press, pp. 337-383, ISBN: 92-9169-121-6.

Li Q, Wu H and Zhang L 2013 Modelling seasonal variation of sea ice in Prydz Bay, Antarctica; Int. J. Offshore. Polar. 23 15-21.

Lindsay R W and Zhang J 2005 The thinning of arctic sea ice, 1988-2003: Have we passed a tipping point? J. Climate 18 4879-4894.

Losch M, Menemenlis D, Campin J M, Heimbach P and Hill C 2010 On the formulation of sea-ice models. Part 1: Effects of different solver implementations and parameterizations; Ocean Model. 33 129-144.

Lucas M, Gihwala K and Viskich M 2014 How are Antarctica and the Southern Ocean responding to climate change? Cover story; Quest 10 16-19.

Mahlstein I, Gent P R and Solomon S 2013 Historical Antarctic mean sea ice area, sea ice trends, and winds in CMIP5 simulations; J. Geophys. Res. Atmos. 118 5105-5110.

Marshall J, Olbers D, Ross H and Wolf-Gladrow D 1993 Potential vorticity constraints on the dynamics and hydrography of the Southern Ocean; J. Phys. Oceanogr. 23 465-487.

Marshall J, Adcroft A, Hill C, Perelman L and Heisey C 1997 A finite volume, incompressible Navier Stokes model for studies of the ocean on parallel computers; J. Geophys. Res. 102(C3) 5753-5766.

Martinson D G and Iannuzzi R A 2003 Spatial/temporal patterns in Weddell gyre characteristics and their relationship to global climate; J. Geophys. Res. 108(C4) 8083, doi: 10.1029/2000JC000538.

Mazloff M, Heimbach P and Wunsch C 2010 An Eddypermitting Southern Ocean state estimate; J. Phys. Oceanogr. 40 880-899.

Orsi A H, Whitworth T and Nowlin W D 1995 On the meridional extent and fronts of the Antarctic Circumpolar Current; Deep. Sea Res. 42 641-673.

Parkinson C L and Cavalieri D J 2012 Antarctic sea ice variability and trends, 1979-2010; The Cryosphere 6 871-880. 
Patra P K, Maksyutov S, Ishizawa M, Nakazawa T, Takahashi T and Ukita J 2005 Interannual and decadal changes in the sea-air $\mathrm{CO}_{2}$ flux from atmospheric inverse modelling; Global Biogeochem. Cycles 19(4) GB4013, doi: 10.1029/2004GB002257.

Polvani L M and Smith K L 2013 Can natural variability explain observed Antarctic sea ice trends? New modelling evidence from CMIP5; Geophys. Res. Lett. 40 3195-3199.

Powell D C, Markus T and Stoessel A 2005 Effects of snow depth forcing on Southern Ocean sea ice simulations; $J$. Geophys. Res. 110 C06001, doi: 10.1029/2003JC002212.

Rayner N A, Parker D E, Horton E B, Folland C K, Alexander L V, Rowell D P, Kent E C and Kaplan A 2003 Global analyses of sea surface temperature, sea ice, and night marine air temperature since the late nineteenth century; J. Geophys. Res. 108, doi: 10.1029/2002JD002670.

Reynolds R W, Smith T M, Liu C, Chelton D B, Casey K S and Schlax M G 2007 Daily high-resolution-blended analyses for sea surface temperature; J. Climate 20 5473-5496.

Rintoul S, Hughes C and Olbers D 2001 The Antarctic circumpolar current system; In: Ocean Circulation and Climate (eds) Siedler G, Church J and Gould J, Academic Press, New York, pp. 271-302.

Rooth C 1982 Hydrology and Ocean Circulation; Progr. Oceanogr. 11 131-149.

Sigmond M and Fyfe J C 2010 Has the ozone hole contributed to increased Antarctic sea ice extent?; Geophys. Res. Lett. 37 L18502, doi: 10.1029/2010GL044301.

Smith W and Sandwell D 1997 Global sea floor topography from satellite altimetry and ship depth soundings; Science 277(5334) 1956-1962.

Stossel A, Zhang Z and Vihma T 2011 The effect of alternative real-time wind forcing on Southern Ocean sea ice simulations; J. Geophys. Res. 116 C11021, doi: 10.1029/ 2011JC007328.

Swart N C and Fyfe J C 2013 The influence of recent Antarctic ice sheet retreat on simulated sea ice area trends; Geophys. Res. Lett. 40 4328-4332.

Takahashi T, Sutherland S C, Wanninkhof R, Sweeney C, Feely R A, Chipman D W, Hales B, Friederich G, Chavez F, Sabine C and Watson A 2009 Climatological mean and decadal change in surface ocean $\mathrm{pCO}_{2}$, and net sea-air $\mathrm{CO}_{2}$ flux over the global oceans; Deep-Sea Res. Part II; Topical Studies in Oceanography 56 554-577.
Thomas D N and Dieckmann G S 2002 Antarctic sea ice - a habitat for extremophiles; Science 295(5555) 641-644.

Timmermann R, Goosse H, Madec G, Fichefet T, Ethe C and Duliere V 2005 On the representation of high latitude processes in the ORCA-LIM global coupled sea ice-ocean model; Ocean Model. 8 175-201.

Timmermann R, Danilov S, Schroter J, Böning C, Sidorenko D and Rollenhagen K 2009 Ocean circulation and sea ice distribution in a finite element global sea ice-ocean model; Ocean Model. 27 114-129.

Timmermann R and Beckmann A 2004 Parameterization of vertical mixing in the Weddell Sea; Ocean Model. 6 83-100.

Timmermann R, Beckmann A and Hellmer H H 2002 Simulations of ice-ocean dynamics in the Weddell Sea 1. Model configuration and validation; J. Geophys. Res. 107(C3) 3024, doi: 10.1029/2000JC000741.

Trenberth K E, Large W G and Olson J G 1990 The mean annual cycle in global ocean wind stress; J. Phys. Oceanogr. 20 1742-1760.

Turner J, Bracegirdle T J, Phillips T, Marshall G J and Hosking J S 2013 An initial assessment of Antarctic sea ice extent in the CMIP5 models; J. Climate 26 1473-1484.

Walsh J E 1983 The role of sea ice in climatic variability: Theories and evidence 1; Atmos. Ocean 21 229-242.

Warren B A 1983 Why is no deep water formed in the North Pacific?; J. Mar. Res. 41 327-347.

Wunsch C 1998 The work done by the wind on the oceanic general circulation; J. Phys. Oceanogr. 28 2332-2340.

Yuan XI 2004 ENSO-related impacts on Antarctic sea ice: A synthesis of phenomenon and mechanisms; Antarctic Science 16 415-425.

Yuan X and Martinson D G 2000 Antarctic sea ice extent variability and its global connectivity; J. Climate 13 1697-1717.

Zhang J 2007 Increasing Antarctic sea ice under warming atmospheric and oceanic conditions; J. Climate 20 2515-2529.

Zhang J and Hibler W D III 1997 On an efficient numerical method for modelling sea ice dynamics; J. Geophys. Res. 102 8691-8702.

Zhang J and Rothrock D A 2003 Modelling global sea ice with a thickness and enthalpy distribution model in generalized curvilinear coordinates; Mon. Wea. Rev. 131 845-861. 